\title{
Phosphatidylserine binding regulates TIM-3 effects on $T$ cell receptor signaling
}

\author{
Courtney M. Smith*, Alice Li, Nithya Krishnamurthy, and Mark A. Lemmon ${ }^{1 *}$
}

Yale Cancer Biology Institute and Department of Pharmacology, Yale University School of Medicine, New Haven, CT, 06520, USA

${ }^{1}$ Lead contact (mark.lemmon@yale.edu)

Correspondence to: courtney.smith@yale.edu or mark.lemmon@yale.edu

Yale Cancer Biology Institute,

Advanced Biosciences Center (ABC) 301, 840 West Campus Drive,

PO Box 27400

West Haven, CT 06516

USA

Tel: $\quad$ (203) 737-7360

Short title: TIM-3 regulation by phosphatidylserine 


\section{SUMMARY}

Co-signaling receptors for the $\mathrm{T}$ cell receptor are important therapeutic targets, with blocking coinhibitory receptors such as PD-1 now central in immuno-oncology. Advancing additional therapeutic immune modulation approaches requires understanding ligand regulation of other cosignaling receptors. One poorly understood therapeutic target is TIM-3 (T cell immunoglobulin and mucin domain containing-3). Which ligands are relevant for TIM-3 signaling is unclear, and different studies have reported it as co-inhibitory or co-stimulatory. Here, we show that TIM-3 promotes NF- $\mathrm{KB}$ signaling and IL-2 secretion following T cell receptor stimulation in Jurkat cells, and is regulated by phosphatidylserine (PS) binding. TIM-3 signaling is stimulated by PS exposed constitutively in cultured Jurkat cells, and can be blocked by mutating the PS-binding site or by occluding this site with an antibody. We also find that TIM-3 signaling alters CD28 phosphorylation. Our findings help clarify conflicting literature results with TIM-3, and inform its exploitation as a therapeutic target.

\section{KEYWORDS}

TIM-3; T cell receptor; phosphatidylserine; Jurkat; signaling; PD-1; CD28; T cell; phosphorylation 


\section{INTRODUCTION}

The functional outcome when an antigen engages the T cell receptor (TCR) depends on the activity of a wide range of 'co-signaling receptors' in T cells [1], which can be stimulatory (like CD28) or inhibitory (like CTLA-4 and PD-1). The co-stimulatory receptors promote T cell activity and play roles in priming naïve $\mathrm{T}$ cells or forming memory $\mathrm{T}$ cells. Conversely, coinhibitory receptors restrain $\mathrm{T}$ cell activity and are important for immunological homeostasis preventing autoimmunity under normal circumstances, but also allowing tumors to evade immune responses in cancer. Both classes of co-receptor have offered important opportunities in immunotherapy, including suppression of co-stimulatory receptor signaling in autoimmunity [2] and suppression of co-inhibitory receptors - or immune checkpoint blockade (ICB) - in cancer $[3,4]$. The regulatory ligands are known for most co-signaling receptors currently targeted therapeutically, as is the designation of the receptor as co-inhibitory or co-stimulatory [5]. An exception to this is TIM-3, or T cell immunoglobulin and mucin domain containing-3, for which multiple ligands have been proposed, and both co-stimulatory and co-inhibitory activities have been described [6-8].

TIM-3 was first identified as a marker of CD4 T helper $1\left(\mathrm{~T}_{\mathrm{H}} 1\right)$ cells and CD8 cytotoxic $\mathrm{T}\left(\mathrm{T}_{\mathrm{C}} 1\right)$ cells [9], and was later identified on exhausted $\mathrm{T}$ cells in chronic viral infection and cancer [10-12]. Early in vivo studies pointed to a co-inhibitory role for TIM-3 [13, 14]. Blocking

TIM-3 engagement in mice with antibodies or soluble TIM-3 extracellular domain was found to increase $\mathrm{T}_{\mathrm{H}} 1$ cell proliferation, and TIM-3 deficient mice showed defects in immune tolerance. In vitro studies have variously reached the conclusion that TIM-3 can either suppress or promote T cell signaling [6, 15-19]. Moreover, TIM-3 does not have a definable intracellular ITIM (immunoreceptor tyrosine-based inhibitory motif) or ITSM (immunoreceptor tyrosine-based 
switch motif) - motifs that normally characterize co-inhibitory receptors and which recruit SH2 domain-containing phosphatases to reduce T cell signaling [20]. Nonetheless, pre-clinical studies have indicated that antibody blockade of TIM-3, in combination with PD-1 blockade, may be a promising therapeutic approach in cancer [21, 22]. Several TIM-3 antibodies are now in clinical trials [23], underlining the need to understand it mechanistically.

Adding further complexity to understanding TIM-3, several regulatory ligands have been reported. The first was the lectin family member galectin-9 [24], which has two $\beta$-galactosidebinding carbohydrate-recognition domains. Galectin-9 is thought to induce T cell death by binding to carbohydrates on TIM-3, although some work has refuted this $[25,26]$. The glycoprotein CEACAM1/CD66a and the alarmin HMGB1 have also been reported as TIM-3 ligands [8], but their mechanism and relevance are not yet clear. Another major TIM-3 ligand is the membrane phospholipid phosphatidylserine (PS), exposed on the surface of cells undergoing apoptosis and other processes [27, 28], including T cell activation [29]. Homology between TIM3 and the known PS receptor TIM-4 [30] initially suggested PS as a ligand. Crystallographic and binding studies have confirmed that TIM-3 binds PS, and TIM-3 can also facilitate binding to and engulfment of apoptotic cells (efferocytosis) by macrophages like its relatives TIM-1 and TIM-4 [31-33]. Importantly, however, the role played by PS binding in modulating TIM-3 function in T cells has not been elucidated - although it was recently reported that the epitopes bound by immunomodulatory TIM-3 antibodies all overlap with the PS binding site [34].

Here, we explored the importance of PS for the effect of TIM-3 on TCR signaling, using a Jurkat cell model. We asked whether PS is a key regulatory ligand for TIM-3, beyond the role of this phospholipid in promoting engulfment of apoptotic cells when TIM-3 is expressed on macrophages. In agreement with several previous studies, we observed a co-stimulatory effect 
when TIM-3 was overexpressed in Jurkat cells. We found that this effect requires the TIM-3 extracellular region, suggesting ligand-dependent regulation. Further, we showed that TIM-3dependent enhancement of TCR signaling is blocked by mutations that prevent PS binding or by an antibody to the PS-binding site. Thus, endogenous PS in our culture system appears to promote TIM-3 effects on TCR signaling. These findings argue that the co-receptor function of TIM-3 specifically depends on PS binding, which has important mechanistic implications for therapeutic targeting of this receptor.

\section{MATERIALS AND METHODS}

\section{Cell culture}

The NF-אB/Jurkat/GFP ${ }^{\mathrm{TM}}$ Transcriptional Reporter cell line was obtained from System Biosciences, and was cultured in RPMI-1640 media supplemented with 10\% FBS, 100 U/ml penicillin, and $100 \mu \mathrm{g} / \mathrm{ml}$ streptomycin at $37^{\circ} \mathrm{C}$ with $5 \% \mathrm{CO}_{2}$ in a humidified environment. HEK293LTV cells (Cell Biolabs Inc.) used to generate lentivirus were cultured in DMEM supplemented with $10 \% \mathrm{FBS}, 100 \mathrm{U} / \mathrm{ml}$ penicillin, and $100 \mu \mathrm{g} / \mathrm{ml}$ streptomycin at $37^{\circ} \mathrm{C}$ in $5 \%$ $\mathrm{CO} 2$ in a humidified environment. Human peripheral blood mononuclear cells (PBMCs) were a generous gift from Susan Kaech. PBMCs were cultured in RPMI 1640 media supplemented with 10\% FBS, 2 mM GlutaMAX (ThermoFisher Scientific), $50 \mu \mathrm{M}$ beta-mercaptoethanol, $100 \mathrm{U} / \mathrm{ml}$ penicillin, and $100 \mu \mathrm{g} / \mathrm{ml}$ streptomycin at $37^{\circ} \mathrm{C}$ with $5 \% \mathrm{CO}_{2}$ in a humidified environment. Raji B cells were obtained from American Type Culture Collection and were cultured in RPMI-1640 media supplemented with $10 \% \mathrm{FCS}, 100 \mathrm{U} / \mathrm{ml}$ penicillin, and $100 \mu \mathrm{g} / \mathrm{ml}$ streptomycin at $37^{\circ} \mathrm{C}$ with $5 \% \mathrm{CO}_{2}$ in a humidified environment. Expi293F cells used for protein expression 
(ThermoFisher Scientific) were cultured in Expi293 media (ThermoFisher Scientific) at $37^{\circ} \mathrm{C}$ in a humidified environment containing $8 \% \mathrm{CO}_{2}$ while shaking.

\section{Plasmids}

pCDEF3-hTIM-3 was a gift from Lawrence Kane (Addgene plasmid \# 49212), and contained the natural variant L119, which was corrected to R119 by site-directed mutagenesis. Full length human TIM-3 (R119) was then sub-cloned into pcDNA3.1(+) using Gibson assembly [35]. Human PD-1 in pENTR223 [36] was a generous gift from Aaron Ring at Yale University. The lentivirus transfer plasmid was a generous gift from the laboratory of Mandar Muzumdar at Yale University and contained AmpR, PuroR under the SV40 promoter, and the gene of interest under the PGK promoter [37]. cDNA fragments encoding human TIM-3 and human PD-1 were subcloned into the lentivirus transfer plasmid. The lentivirus envelope and packaging plasmids pMD2.G and pCMV delta R8.2 were gifts from Didier Trono (Addgene plasmids \# 12259 and 12263). Plasmids containing human TIM-1 and human TIM-4 were obtained from Origene. For expression of extracellular regions, cDNA fragments encoding the ECRs of human TIM-3, TIM1, and TIM-4 were sub-cloned into pcDNA3.1(+) vector using Gibson assembly, introducing a C-terminal hexa-histidine tag.

TIM-1-3, TIM-4-3, and PD-1/TIM-3 chimerae were constructed in the lentivirus transfer vector using Gibson assembly. The TIM-3 $3^{\mathrm{F} 40 \mathrm{~A}}$ and TIM-3 $3^{\text {I96A/M97A }}$ variants were generated by QuikChange site-directed mutagenesis (Agilent) in pcDNA3.1 (+) for ECR protein expression and in the lentivirus transfer vector for cellular studies. Sequencing was performed to validate all plasmids before use. 


\section{Antibodies}

Cells were stained for flow cytometry analysis with phycoerythrin-conjugated forms of antiTIM-3 (R \& D Systems, catalog \#FAB2365P), anti-PD-1 (BioLegend, catalog \#329905), antiTIM-1 (BioLegend, catalog \#353903), anti-TIM-4 (BioLegend, catalog \#354003), anti-PD-L1 (also labeled with Dazzle 594: BioLegend, catalog \#329731), or with an unlabeled TIM-3 primary antibody (R \& D Systems, catalog \#AF2365) using a phycoerythrin-conjugated anti-goat secondary antibody for detection (R \& D Systems, catalog \# F0107). PBMCs were stained with phycoerythrin-Dazzle694-labeled anti-CD3 (Biolegend, catalog \#317345), PerCP/Cy5.5 ${ }^{\mathrm{TM}}$ labeled anti-CD8 (Biolegend, catalog \#301031), BB515-labeled anti-CD4 (BD Biosciences, catalog \#564420), and phycoerythrin-labeled anti-TIM-3 (R \& D Systems, catalog \#FAB2365P), Western blot analysis was performed with anti-Zap70 pY319 (Cell Signaling Technology, catalog \#2701), anti-LAT pY191 (Cell Signaling Technology, catalog \#3584), anti-PLC $\gamma$ pY783 (Cell Signaling Technology, catalog \#14008), anti-ERK1/2 pT202/pY204 (Cell Signaling Technology, catalog \#9106), anti-Grb2 (Cell Signaling Technology, catalog \#3972), anti-CD28 pY218 (Sigma Aldrich, catalog \#SAB4504133), anti-CD28 pY191 (Cell Signaling Technology, catalog \#16399), anti-AKT pT308 (Cell Signaling Technology cat\# 2965), anti-TIM-3 (R \& D Systems, catalog \#AF2365), anti-TIM-3 (Abcam, catalog \#ab241332), and anti-PD-1 (Cell Signaling Technology, catalog \#86163). For TCR stimulation, anti-CD3 clone OKT3 (BioLegend, catalog \#317326) and anti-CD28 clone CD28.2 (BioLegend, catalog \#302943) were used. For functional studies, anti-TIM-3 clone F38.2E2 (ThermoFisher Scientific, catalog \#163109-85) was used. 


\section{Lentivirus transduction}

Lentiviruses were generated by co-transfecting HEK293 LTV cells with lentivirus transfer, envelope, and packaging plasmids using the Mirus Bio TransIT-Lenti Transfection Reagent, according to the manufacturer's protocol. Briefly, HEK293 LTV cells were cultured to 80-95\% confluency. Plasmids were mixed with Opti-MEM and TransIT-Lenti Transfection Reagent and were incubated at room temperature for 10 min before being added to HEK293 LTV cells and incubating at $37^{\circ} \mathrm{C}, 5 \% \mathrm{CO}_{2}$. After $48 \mathrm{~h}$, virus-containing medium was collected and filtered through a $0.22 \mu \mathrm{m}$ filter. Filtered virus suspension was then added to Jurkat cells ( $2 \times 10^{5}$ cells), and cells were transduced with lentivirus by spinfection (spinning at $800 \mathrm{xg}$ for $30 \mathrm{~min}$ at $32^{\circ} \mathrm{C}$ ) 'spinoculation' [38] in sealed aerosol containment lids. Three days after transfection, medium was replaced and cells were selected with puromycin $(1 \mu \mathrm{g} / \mathrm{ml})$ for 2 days. After selection, medium was replaced again and cells were allowed to recover. Following selection, receptor expression was verified by flow cytometry. Cells were washed in FACS Buffer: $10 \%$ FBS plus $0.1 \% \mathrm{NaN}_{3}$ in phosphate-buffered saline (PBS) $0.22 \mu \mathrm{m}$ filtered. They were then stained with antibodies in the dark. Cells were rewashed and then analyzed on a FACSMelody (Becton Dickinson), with a four-color set up (488 nm and $561 \mathrm{~nm}$ lasers with 527/32, 700/54, 582/15, and 613/18 filter sets).

\section{Expression of TIM-3 on peripheral blood mononuclear cells (PBMCs)}

After overnight recovery, thawed PBMCs were transferred to a 24-well plate coated with

$1 \mu \mathrm{g} / \mathrm{ml} \alpha \mathrm{CD} 3$, and soluble $\alpha \mathrm{CD} 28(1 \mu \mathrm{g} / \mathrm{ml})$ was added to the culture to promote outgrowth of T cells. Cells were maintained between 0.25 and $0.5 \times 10^{6}$ cells per $\mathrm{cm}^{2}$ with $\alpha \mathrm{CD} 3 / \alpha \mathrm{CD} 28$ stimulation for 7 days to promote expression of TIM-3 [39]. After 7 days, PBMCs were washed 
in FACS Buffer (10\% FBS plus $0.1 \% \mathrm{NaN}_{3}$ in phosphate-buffered saline (PBS) $0.22 \mu \mathrm{m}$

filtered). PBMCs were then stained with labeled anti-CD3, anti-CD8, anti-CD4, and anti-TIM-3. Cells were then washed again in FACS Buffer before analysis on a FACSMelody. PBMCs were first subjected to doublet discrimination before analyzing for expression of cell surface markers, as shown in Supplementary Figure 1.

\section{$\mathrm{NF}-\kappa \mathrm{B}$ reporter assay}

NF- $\kappa$ B GFP reporter Jurkat cells were resuspended in RPMI-1640 media with 0\% FBS and were serum starved for $4 \mathrm{~h}$. After starvation, cells were counted and $5 \times 10^{5}$ cells were plated in a Vbottom 96-well plate and stimulated with $\alpha \mathrm{CD} 3 / \alpha \mathrm{CD} 28(1 \mu \mathrm{g} / \mathrm{ml}$ each, or $0.5 \mu \mathrm{g} / \mathrm{ml}$ for $\alpha C D 28)$, with additional treatments as stated in figure legends. In experiments investigating effects of anti-TIM-3 (F38.2E2), cells were pre-treated with TIM-3 antibody for $1 \mathrm{~h}$ before stimulation with $\alpha \mathrm{CD} 3 / \alpha \mathrm{CD} 28$. Cells were returned to the incubator at $37^{\circ} \mathrm{C}, 5 \% \mathrm{CO}_{2}$ for $16 \mathrm{~h}$. Cells were then washed in FACS Buffer, stained with antibodies, and rewashed prior to analysis using the FACSMelody. Data were analyzed using FlowJo software. GFP signal was quantified for single cells, as determined through SSC-H vs. SSC-W and FSC-H vs. FSC-W gates.

\section{Analysis of IL-2 secretion}

NF- $\kappa$ B GFP reporter Jurkat cells were resuspended in RPMI-1640 media with 0\% FBS and were serum starved for $4 \mathrm{~h}$. After starvation, cells were counted and $5 \times 10^{5}$ cells were plated in a Vbottom 96-well plate. Cells were stimulated with $1 \mu \mathrm{g} / \mathrm{ml} \alpha \mathrm{CD} 3$ (BioLegend, catalog \#317326) plus 0.5 or $1 \mu \mathrm{g} / \mathrm{ml} \alpha \mathrm{CD} 28$ (BioLegend, catalog \#302943), and returned to the incubator at $37^{\circ} \mathrm{C}$, $5 \% \mathrm{CO}_{2}$, for $16 \mathrm{~h}$. In experiments analyzing the effect of anti-TIM-3 F38.2E2, cells were pre- 
treated with anti-TIM-3 for $1 \mathrm{~h}$ before stimulation with $\alpha \mathrm{CD} 3 / \alpha \mathrm{CD} 28$. In experiments using Raji B cell-based stimulation, Raji B cells were loaded with $30 \mathrm{ng} / \mathrm{ml}$ Staphylococcal enterotoxin E (Toxin Technology Inc., catalog \#ET404) for $30 \mathrm{~min}$ at $37^{\circ} \mathrm{C}$ and were washed in serum-free RPMI-1640 media to remove excess toxin. Jurkat NF-אB GFP reporter cells were serum starved in RPMI-1640 media with 0\% FBS for $3 \mathrm{~h}$. After starvation, 2 x $10^{5}$ Jurkat cells were mixed with $10^{5}$ SEE-loaded Raji B cells per well in a 96-well U-bottom plate, as described [40]. The plate was centrifuged for $1 \mathrm{~min}$ at $300 \mathrm{x}$ g to initiate cell contact, and plate was returned to incubator at $37^{\circ} \mathrm{C}, 5 \% \mathrm{CO}_{2}$, for $6 \mathrm{~h}$. Following antibody or cell-based stimulation, media was collected for analysis of IL-2 secretion by ELISA (R \& D Systems, cat \#D2050), following the IL-2 Quantikine ELISA manual. Experiments were performed in technical duplicate and biological triplicate.

\section{Western blot analysis}

NF- $\mathrm{KB}$ GFP reporter Jurkat cells were serum starved and stimulated as above, with additional treatments as stated in figure legends. Where wortmannin was used (in Figure 2C), cells were pre-treated with drug for $1 \mathrm{~h}$ before stimulation. Cells were pelleted by centrifugation $(800 \mathrm{x} \mathrm{g}$ for $1.5 \mathrm{~min}$ ) in the last 1.5 minutes of stimulation. Supernatant was removed, and cells were lysed in ice cold Lysis Buffer (Cell Signaling Technology) with freshly added cOmplete protease inhibitor (Roche) and PhosSTOP phosphatase inhibitor (Roche). Lysates were clarified by centrifugation $\left(10,000 \mathrm{x}\right.$ g for $10 \mathrm{~min}$ at $\left.4^{\circ} \mathrm{C}\right)$, and clarified lysate was isolated. Lysates were mixed with NuPAGE LDS Sample Buffer (Invitrogen) plus dithiothreitol (DTT) and were boiled for 8 min. Samples were then analyzed by SDS-PAGE using NuPAGE 4-12\% Bis-Tris gels. Gels were transferred to $0.22 \mu \mathrm{m}$ nitrocellulose membranes using the Xcell Surelock Electrophoresis 
system (ThermoFisher Scientific). To probe multiple proteins simultaneously without requiring stripping and reprobing, the multistrip Western blotting procedure was used [41], in which horizontal strips are excised from the nitrocellulose membrane corresponding to molecular weight guides to allow probing of one blot with several antibodies. Membranes were blocked with 4\% BSA in Tris-buffered saline plus Tween20 (TBS-T), probed with primary antibody for $1 \mathrm{~h}$ to overnight, and then probed with HRP-tagged secondary antibodies for $1 \mathrm{~h}$. Detection was by enhanced chemiluminescence using SuperSignal Western Pico PLUS Chemiluminescent substrate (ThermoFisher Scientific), with visualization and quantitation using a Kodak Image Station (Kodak Scientific).

\section{Detection of Annexin V staining by flow cytometry}

PerCP-Cy ${ }^{\mathrm{TM}} 5.5$ or FITC-labeled Annexin V were obtained from BioLegend (catalog \#640936 and 640905). As specified by the manufacturer, cells were washed twice with ice cold PBS and then resuspended in $10 \mathrm{mM}$ HEPES pH 7.5, $140 \mathrm{mM} \mathrm{NaCl}, 2.5 \mathrm{mM} \mathrm{CaCl}_{2}$ (binding buffer). Annexin V-PerCP-Cy5.5 or -FITC was added to each sample and incubated for 15 min in the dark. Additional binding buffer was added to each sample, followed by analysis using FACSMelody (Becton Dickinson) and FlowJo software.

\section{Detection of Annexin V staining by widefield fluorescence microscopy}

AlexaFluor® 647-labeled Annexin V was obtained from Biolegend (catalog \#640911). As

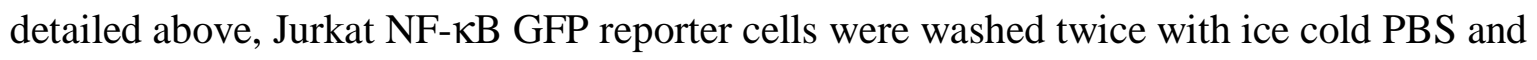
resuspended in Annexin V binding buffer (10 mM HEPES pH 7.5, $140 \mathrm{mM} \mathrm{NaCl,} 2.5 \mathrm{mM}$ $\mathrm{CaCl}_{2}$ ). Annexin $\mathrm{V}$-AlexaFluor ${ }^{\circledR} 647$ was added to cells and incubated for 15 minutes in the 
dark. Cells were then fixed in $4 \%$ paraformaldehyde in PBS with $2.5 \mathrm{mM} \mathrm{CaCl}_{2}$ for 15 minutes. Annexin V-stained cells were cytospun onto microscope slides at 800 RPM for 5 minutes. Cells were fixed with ProLong ${ }^{\mathrm{TM}}$ Diamond Antifade Mountant with DAPI (ThermoFisher Scientific, catalog \#P36966) per the manufacturer's instructions. Images were collected with a Nikon Eclipse Ti2 widefield fluorescence microscope using a Nikon Plan Apo $\lambda$ 40x 0.95 N.A. objective. Excitation was provided by a Sola light engine with a DAPI or Cy5 filter cube sets. Emission was collected by an sCMOS pco.edge camera. Images were analyzed with FIJI software.

\section{Protein expression and purification}

As specified in the Expi293 Expression System manual, Expi293F cells were cultured to reach a density of $4.5-5.5 \times 10^{6}$ cells $/ \mathrm{ml}$ on the day of transfection, and seeded at $3 \times 10^{6}$ cells $/ \mathrm{ml}$. A transfection mixture containing DNA vector ( $1 \mu \mathrm{g}$ per $\mathrm{ml}$ of culture to be infected), Expifectamine reagent (ThermoFisher Scientific), and Opti-MEM was then incubated at room temperature for $10 \mathrm{~min}$ and subsequently added to the culture. Cells were returned to the humidified incubator at $37^{\circ} \mathrm{C}, 8 \% \mathrm{CO}_{2}$. Expi293 enhancers (ThermoFisher Scientific) were added 18-22 $\mathrm{h}$ after transfection, and the culture was harvested 4-6 days later by centrifugation (1,000 RPM). Culture supernatant was collected and diafiltered against 4 times the culture volume with $10 \mathrm{mM}$ HEPES pH 8, $150 \mathrm{mM} \mathrm{NaCl}$ (TIM Buffer 1). Nickel affinity chromatography was performed on the diafiltered supernatant with Ni-NTA agarose (Qiagen), eluting fractions with increasing concentrations of imidazole in TIM Buffer 1. Protein-containing fractions were pooled, diluted to $50 \mathrm{mM} \mathrm{NaCl}$, filtered $(0.22 \mu \mathrm{m})$, and injected onto a Fractogel TMAE column (EMD Millipore) equilibrated in $25 \mathrm{mM}$ HEPES pH 8 at $50 \mathrm{mM}$ NaCl. Protein 
was eluted using a gradient from 50 to $700 \mathrm{mM} \mathrm{NaCl}$ in $25 \mathrm{mM}$ HEPES pH 8. Peak fractions $(\sim 150 \mathrm{mM} \mathrm{NaCl})$ were collected, concentrated using a $10 \mathrm{kDa}$ MWCO centrifugal filter (EMD Millipore), filtered $(0.22 \mu \mathrm{m})$, and applied to a Superose 12 10/300 column (Cytiva Life Sciences) for gel filtration in TIM Buffer 2 (10 mM HEPES pH 7.6, $150 \mathrm{mM} \mathrm{NaCl}$ ). Peak fractions were collected, concentrated using a $10 \mathrm{kDa}$ MWCO centrifugal filter (EMD Millipore) and filtered $(0.22 \mu \mathrm{m})$. SDS-PAGE was performed to confirm protein size and purity. Protein concentration was determined by $280 \mathrm{~nm}$ absorbance using a NanoDrop spectrophotometer (ThermoFisher Scientific) with calculated extinction coefficients.

\section{Vesicle preparation}

Lipids were purchased from Avanti Polar Lipids in chloroform solution, including dioleoylphosphatidylcholine (DOPC), dioleoylphosphatidylserine (DOPS), dioleoylphosphatidic acid (DOPA), and dioleoylphosphatidylethanolamine (DOPE). Lipid solutions were combined at the appropriate molar ratios in a glass vial. Chloroform was blown off under a stream of nitrogen gas, fully drying the lipid mixture under vacuum. Lipid mixtures were rehydrated with $10 \mathrm{mM}$ HEPES pH 7.6, $150 \mathrm{mM} \mathrm{NaCl}$, vortexed to mix, and subjected to at least 10 freeze-thaw cycles, where the suspension was frozen in liquid nitrogen and thawed in a warm sonicating water bath, to generate unilamellar vesicles. Vesicle suspensions were stored at $-20^{\circ} \mathrm{C}$. Before use, thawed sonicated vesicles were extruded using a $100 \mathrm{~nm}$ filter membrane in an Avanti Mini Extruder.

\section{Surface plasmon resonance studies}

Surface plasmon resonance (SPR) analyses of protein-lipid interactions were performed using a Biacore 3000 instrument as described [42, 43]. Lipid vesicles containing DOPC or the specified 
percentage (mole/mole) of lipid in a DOPC background were immobilized by flowing lipid vesicles across an L1 chip (Cytiva) in TIM Buffer 2 (10 mM HEPES pH 7.6, $150 \mathrm{mM} \mathrm{NaCl).}$ After immobilization, purified proteins were flowed across the chip at varying concentrations in the presence or absence of $1 \mathrm{mM} \mathrm{CaCl}_{2}$. Resonance units detected by the Biacore 3000 were corrected for background (DOPC) binding on a separate sensorchip surface, and were plotted against protein concentration. Curves were fit using the equation: $\mathrm{RU}_{\max }=\mathrm{B}_{\max } \mathrm{x}[\mathrm{TIM}] /\left(\mathrm{K}_{\mathrm{d}}+\right.$ [TIM]), and apparent $\mathrm{K}_{\mathrm{d}}$ was estimated from these curves.

\section{Quantification and statistical analysis}

Experiments were completed with at least three biological repeats unless noted otherwise. For transcriptional reporter experiments, each independent experiment included three technical repeats. In addition to mean fluorescence intensity, the percent of GFP-positive cells and the median fluorescence intensity of GFP-positive cells were quantitated for transcriptional reporter experiments, to ascertain whether analysis method influenced interpretation. In all cases, the result was the same as seen when assessing mean fluorescence intensity as done in the figures lending confidence to our analysis and its qualitative conclusions. All quantitated values are represented as mean values \pm standard deviation. Statistical analysis was performed with twotailed, unpaired Student's t-test. 


\section{RESULTS}

\section{TIM-3 promotes TCR signaling when overexpressed in Jurkat cells}

In considering possible mechanisms of TIM-3 signaling, a key question to resolve [8] is whether TIM-3 functions in T cells as a co-inhibitory or co-stimulatory receptor. In vitro studies have suggested both. Lee et al. (2012) reported that elevating TIM-3 expression in Jurkat cells inhibits the NFAT pathway. Moreover, Tomkowicz et al. (2015) reported that TIM-3 overexpression suppressed NFAT and NF- $\kappa \mathrm{B}$ signaling following TCR activation with $\alpha \mathrm{CD} 3 / \alpha \mathrm{CD} 28$. In stark contrast, Lee et al. (2011) reported that expressing either murine TIM-3 or human TIM-3 in Jurkat cells had the opposite effect - promoting both NF- $\mathrm{KB}$ and NFAT signaling. Other studies have also supported a positive role for TIM-3 in acute activation of murine CD8 T cells [6, 16]. Thus, these and other studies argue that the influence of TIM-3 can be positive or negative depending on its T cell type and possibly its expression level [44]. Moreover, Avery et al. (2018) posited that, in some settings, TIM-3 is more similar to co-stimulatory receptors than to inhibitory receptors like PD-1.

To establish a system for studying TIM-3 regulation, we asked how its overexpression affects TCR activation in Jurkat cells - a useful model system for studying TCR signaling [45]. We first established that TIM-3 was undetectable by flow cytometry or Western blotting in Jurkat cells (Figure 1A) - in agreement with others [17] - and was not inducible by TCR stimulation. We then used lentiviral delivery of TIM-3 to generate stably expressing (TIM- $3^{+}$)

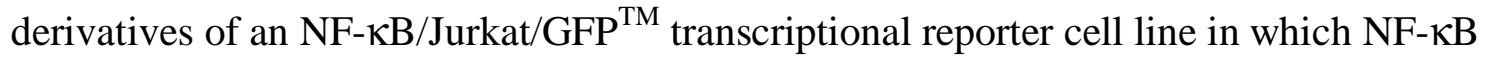
activation downstream of TCR stimulation promotes GFP expression. Importantly, we confirmed that levels of TIM-3 seen following viral transduction of Jurkat NF- $\kappa B$ GFP Reporter cells were similar to that observed in human primary T cells (Supplementary Figure 1). 
Stimulating NF- $\kappa \mathrm{B}$ reporter Jurkat cells with antibodies against CD3 and CD28 $(\alpha \mathrm{CD} 3 / \alpha \mathrm{CD} 28)$ to mimic antigen binding and TCR activation promoted NF- $\kappa \mathrm{B}-\mathrm{dependent} \mathrm{GFP}$ expression as expected [46]. The GFP signal was significantly increased with TIM-3 expression only after T cell stimulation (Figures 1B,C), consistent with key previous studies summarized above [17] and suggesting a co-stimulatory role for TIM-3 in Jurkat cell activation. By contrast, PD-1 overexpression in the same NF- $\mathrm{KB} /$ Jurkat/GFP $^{\mathrm{TM}}$ cells had no significant effect on TCRactivated NF- $\kappa \mathrm{B}$ signaling (Figure $1 \mathrm{C}$ ), as expected in the absence of PD-L1 to engage PD-1 in these experiments (Supplementary Figure 2A). In parallel experiments, also consistent with previous studies [17], ELISA assays showed that TIM-3 expression substantially increased the level of IL-2 production induced by TCR activation with $\alpha \mathrm{CD} 3 / \alpha \mathrm{CD} 28$ (Figure 1D) - again supporting a co-stimulatory role for TIM-3.

We also stimulated Jurkat cells with Staphylococcal enterotoxin E (SEE)-loaded Raji B cells as antigen-presenting cells to engage the TCR and other key signaling molecules in an immunological synapse (IS). TIM-3 was recently reported to be recruited to the IS during Raji B cell activation of Jurkat T cells [47]. As we observed with antibody stimulation alone, Raji cell activation of Jurkat cells expressing TIM-3 caused them to secrete elevated levels of IL-2 compared to parental cells (Figure 1E), showing that the ability of TIM-3 to promote T cell activation is preserved with IS formation. Together, these data support a co-stimulatory role of TIM-3 in Jurkat T cells when activated by antibodies or by cell-based methods.

\section{Effects of TIM-3 overexpression on signaling responses to $\alpha \mathrm{CD} 3 / \alpha \mathrm{CD} 28$}

To investigate how TIM-3 expression might modulate T cell signaling, we used Western blotting to monitor phosphorylation of components associated with TCR activation after stimulation with 
$\alpha \mathrm{CD} 3 / \alpha \mathrm{CD} 28$. Few differences could be detected when assessing phosphorylation of Zap70, PLC $\gamma 1$, ERK1/2, or LAT in parental and TIM-3 ${ }^{+}$cells (Supplementary Figure 3). Some experiments did suggest that phosphorylation of Zap70 and LAT is slightly greater and more sustained in TIM-3 overexpressing cells (Supplementary Figures 3B,E), but this did not reach statistical significance. Levels and dynamics of phosphorylation of these proteins also appeared essentially unchanged by PD-1 overexpression (Supplementary Figure 3).

One difference that did reach significance (Figure 2) was seen in the level of CD28 phosphorylation, which was modestly increased in TIM-3 overexpressing cells. This effect was seen for both Y191 phosphorylation (Figure 2A) and Y218 (Figure 2B) at the 5-min time point. Elevated phosphorylation was seen at both sites following $\alpha \mathrm{CD} 3 / \alpha \mathrm{CD} 28$ stimulation in parental cells, as expected [48], but TIM-3 expression increased the magnitude of the response by 50\% - with no apparent elevation of baseline CD28 phosphorylation. Intriguingly, Y191 phosphorylation also seemed to be significantly longer-lived in TIM- $3^{+}$cells (Figure $2 \mathrm{~A}$, Supplementary Figure 3F). Phosphorylation of Y218 in CD28 has been reported to be important for NF- $\kappa \mathrm{B}$ activation by CD3/CD28 ligation in Jurkat and primary CD4 T cells [49], consistent with our results for $\mathrm{NF}-\kappa \mathrm{B}$ activation. Moreover, phosphorylation of all three distal tyrosines in the CD28 tail (including Y218) appears to be required for stimulation of IL-2 secretion by T cells [50]. Thus, alterations in the extent of CD28 phosphorylation and/or its dynamics may be important for the increased NF- $\mathrm{KB}$ signaling and IL-2 secretion seen when TIM-3 is overexpressed in Jurkat cells. Phosphorylation of Y191 in CD28 promotes recruitment of phosphoinositide 3-kinase (PI3K) to CD28 [51, 52], and the consequences of altering its phosphorylation are likely blunted in Jurkat cells, which lack PTEN [53]. We did consider that the constitutively high levels of PI3K products seen in Jurkat cells might be responsible for the 
change in CD28 phosphorylation. However, as shown in Figure 2C, the effect of TIM-3

expression on levels of CD28 phosphorylation was maintained in the presence of the PI3K inhibitor wortmannin - indicating no dependence on PI3K activity.

\section{The TIM-3 extracellular region is required for its activity in Jurkat cells}

We next chose to exploit the ability of TIM-3 to enhance NF- $\kappa B$ signaling in the GFP-reporter Jurkat cell line to investigate how the extracellular region of TIM-3 regulates its function, and to understand which of TIM-3's ligand(s) are important. Lee et al. (2011) previously used a similar strategy to investigate signaling requirements of the TIM-3 cytoplasmic tail. They reported the surprising finding that deletion of the TIM-3 extracellular region did not abolish its ability to enhance $\alpha \mathrm{CD} 3 / \alpha \mathrm{CD} 28$-induced NFAT activation [17]. As summarized below, our results contrast with this finding and suggest an important regulatory function for the extracellular region.

Since NF- $\mathrm{KB}$ signaling in the Jurkat reporter cell line was increased by expression of TIM-3, but not of PD-1, we asked whether PD-1/TIM-3 chimerae would preserve this effect which they should if the TIM-3 intracellular region is sufficient for signaling. We replaced the TIM-3 extracellular region with that from PD-1, in 'PTT' or 'PPT' chimerae (Figure 3A) that retain either the TIM-3 (PTT) or PD-1 (PPT) transmembrane (TM) domain. After generating Jurkat reporter cells stably expressing these chimerae at levels similar to full-length TIM-3 (see Supplementary Figures $2 \mathrm{~B}, \mathrm{E}$ ), we assessed their ability to enhance NF- $\kappa \mathrm{B}$ activation by

$\alpha \mathrm{CD} 3 / \alpha \mathrm{CD} 28$. As shown in Figures 3B and C, PTT and PPT cells displayed a slight increase in NF- $\kappa \mathrm{B}$ activation compared to parental and PD-1 reporter cells, but not to the same extent as TIM-3 cells, arguing that the TIM-3 extracellular region does play an important role in its 
signaling effects in Jurkat cells. One possibility is that TIM-3 interacts constitutively with the

TCR or other cellular components to influence the effects of TCR stimulation. Alternatively, it is possible - and perhaps more likely - that TIM-3 is engaged by one of its extracellular ligands in

Jurkat cell cultures. Indeed, it was previously shown that a biotinylated form of the soluble TIM-

3 extracellular region associates with the surface of CD4 T cells in flow cytometry studies [13,

14], and we know that the TIM-3 ligand PS is exposed on the surface of activated T cells,

following antigen recognition [29], consistent with this possibility. Interestingly, expression of

PTT promoted NF- $\mathrm{KB}$ signaling to a slightly greater extent than PPT, possibly implicating the

TIM-3 TM domain as recently suggested by Kane and colleagues [47].

\section{Extracellular regions of other TIM family members can substitute for that of TIM-3}

As a first step in understanding the importance of engagement of the TIM-3 extracellular region by its ligands (and what it/they might be), we generated a second set of chimeric receptors that should retain affinity for phosphatidylserine (PS) but not for other proposed TIM-3 ligands. We replaced the TIM-3 extracellular region, which contains the PS-binding pocket, with that of TIM-1 or TIM-4 (which also bind PS - see below), generating the TIM-1-3 and TIM-4-3 chimerae (Figure 3D). These chimerae retain the TIM-3 transmembrane domain and intracellular region. They should not bind to galectin-9, CEACAM1, or HMGB $1[8,54]$, and would be unlikely to retain specific TIM-3 extracellular interactions with TCR components. After generating Jurkat NF- $\mathrm{BB}$ reporter cells stably expressing these chimeric receptors on the cell surface (Supplementary Figures 2C-E), we asked if they retained the ability to increase $\alpha \mathrm{CD} 3 / \alpha \mathrm{CD} 28$-stimulated NF- $\kappa \mathrm{B}$ activation. As shown in Figures 3E and F, TIM-1-3 and TIM4-3 enhanced NF- $\mathrm{BB}$ activation to a similar extent as seen for TIM-3 in parallel experiments. 
Chimerae with the TIM-3 intracellular region that retain extracellular PS-binding thus seem to preserve the ability to enhance TCR signaling seen for TIM-3.

\section{Phosphatidylserine exposed in Jurkat cell culture may engage TIM-3}

We next asked if TIM-3 signaling could be modulated by adding its putative ligand, PS. We began by quantifying $\alpha \mathrm{CD} 3 / \alpha \mathrm{CD} 28$-stimulated NF- $\kappa \mathrm{B}$ activity in TIM- $3^{+}$cells after adding unilamellar vesicles containing high levels of PS. Vesicles containing 20\% (mole/mole) dioleoylphosphatidylserine (DOPS) in a background of dioleoylphosphatidylcholine (DOPC) had no effect on NF- $\kappa B$ activity in parental Jurkat cells, but also failed to modulate NF- $\kappa$ B activity in cells expressing TIM-3 to a statistically significant degree when compared with pure PC vesicles (Supplementary Figures 4A,B). We therefore hypothesized that Jurkat cells in culture might expose PS on their surface, which could correspond to the previously observed TIM-3 ligand expressed on CD4 T cells $[13,14]$. Indeed, E. coli-derived recombinant murine TIM-3 IgV domain was shown to bind T cells, fibroblasts and macrophages from several species [55] consistent with recognition of a conserved component of these cells, such as PS. As a specific test of the hypothesis that PS on the surface of Jurkat cells promotes TIM-3 effects in our studies, we asked whether adding excess annexin $\mathrm{V}-\mathrm{a}$ known PS-binding protein - might block surfaceexposed PS and suppress TIM-3-dependent elevation of NF- $\kappa \mathrm{B}$ activity. Unfortunately, adding annexin V elevated TCR-driven NF- $\kappa \mathrm{B}$ signaling independently of TIM-3 expression (Supplementary Figures 4C,D), making this experiment uninterpretable.

Annexin V did prove useful for assessing PS exposure on our Jurkat cells, however, and revealed that PS is indeed exposed on their surface in our cultures - presumably as cells undergo apoptosis and/or activation, two processes known to lead to PS exposure on the cell surface [27, 
56, 57]. We stained cells with fluorescently labeled (PerCP-Cy $\left.{ }^{\mathrm{TM}} 5.5\right)$ annexin $\mathrm{V}$, and flow cytometry analysis showed that both parental and virally-transduced TIM- $3^{+} \mathrm{NF}-\kappa \mathrm{B}$ reporter Jurkat cells expressed PS on their surface at clearly detectable levels (Figure 4A). Interestingly, most cells showed only low levels of PS exposure (peak signal 400 ), but a small population had high levels of PS exposure $\left(\sim 10^{5}\right)$. As a secondary approach, we also imaged cells stained with fluorescently-labeled (AlexaFluor® 647) Annexin V prior to fixation, and demonstrated Annexin $\mathrm{V}$ staining of both parental and TIM- $3^{+} \mathrm{NF}-\kappa \mathrm{B}$ reporter Jurkat cells (Figure 4B). These data suggest that sufficient PS may be exposed in our cellular experiments to engage TIM-3 and promote its signaling in Jurkat cells. The fact that adding PS-containing vesicles had no further influence on NF- $\mathrm{KB}$ activity suggests that the PS levels in culture may be near saturation and/or may represent an optimal lipid composition that is not recapitulated by our synthetic vesicles. These data prompted us to ask whether (and how) PS functions as a TIM-3 ligand to modulate $\mathrm{NF}-\kappa \mathrm{B}$ signaling in our experiments.

\section{Phospholipid binding by human TIM extracellular regions}

Before attempting to modulate PS binding by TIM-3 in our cellular experiments, we wanted to understand its PS-binding properties and compare them with those of TIM-1 and TIM-4, the original PS receptor [30]. We expressed the complete soluble TIM protein extracellular regions (sTIM proteins), containing the IgV and mucin domains, in Expi293 cells and used surface plasmon resonance (SPR) to measure their binding to membranes containing $20 \%$ (mole/mole) dioleoylphosphatidylserine (DOPS) in a background of dioleoylphosphatidylcholine (DOPC) as described [42]. sTIM-3 bound to these membranes with an apparent dissociation constant $\left(\mathrm{K}_{\mathrm{d}}\right.$ app) of $9.70 \pm 4.20 \mu \mathrm{M}$ in the presence of $1 \mathrm{mM} \mathrm{CaCl}_{2}$ (Figure 4C). The human sTIM-1 and 
sTIM-4 proteins bound significantly more strongly to the same membranes under identical conditions, with $\mathrm{K}_{\mathrm{d}, \mathrm{app}}$ values of $0.35 \pm 0.05 \mu \mathrm{M}$ and $0.77 \pm 0.32 \mu \mathrm{M}$ respectively (Figure 4C). The relative affinities that we observed here reflect what has been reported for murine TIM proteins using ELISA-type assays [31, 32] and other approaches [33], with sTIM-3 binding PS membranes 12-27 fold more weakly than sTIM-1 or sTIM-4. The actual $\mathrm{K}_{\mathrm{d} \text {, app }}$ values that we report are substantially weaker than those suggested using ELISA methods (which were in the $\mathrm{nM}$ range), which is typical for multivalent systems when comparing results from direct binding studies such as SPR with those from ELISA assays $[43,58]$. Our $\mathrm{K}_{\mathrm{d} \text {, app }}$ values are in the same range as those measured for other PS binding proteins, pleckstrin homology domains and other peripheral membrane proteins $[42,59,60]$, and indeed, for recognition of the prototypical T cell co-receptors CD28 and PD-1 for their respective ligands, CD80/86 [61] and PD-L1 [62].

In additional binding studies (Supplementary Figure 5), we further found that the presence of $\mathrm{Ca}^{2+}$ ions increased the PS-binding affinities of sTIM-1 and sTIM-4 by $\sim 10$-fold, but increased the affinity of sTIM-3 for PS by just 2-fold (Supplementary Figure 5A, Supplementary Table 1) - consistent with previous work [33]. We also asked whether the sTIM proteins can bind other phospholipids known to become exposed on the cell surface during cell death, namely phosphatidic acid (PA) and phosphatidylethanolamine (PE) [63, 64]. sTIM-1, sTIM-3, and sTIM-4 all bound to 20\% PA-containing membranes, but saturated at a slightly lower level than on membranes containing the same level of PS (Supplementary Figures 5C-E). Interestingly, inclusion of 5\% PA also enhanced binding of all sTIM proteins to membranes containing 20\% PS (Supplementary Figures 5F-H), such that sTIM-3 bound more strongly to membranes containing $20 \%$ PS plus $5 \%$ PA than to membranes containing $20 \%$ or $25 \%$ PS (Supplementary Figure 5I). Only sTIM-1 showed significant binding to membranes containing 
the zwitterionic phospholipid PE (Supplementary Figure 5C). This is consistent with a previous report [65] that also indicated that PE on the surface of apoptotic cells promotes their TIM-1mediated phagocytosis.

\section{Mutations that impair TIM-3 binding to PS reduce its impact on T cell signaling}

Reasoning that the effect of TIM-3 expression on TCR signaling in Jurkat cells reflects TIM-3 engagement by PS on the cell surface in our experiments, we next mutated TIM-3 to reduce its PS-binding affinity. Our goal was to ask whether such mutations diminish the effect of TIM-3 on TCR signaling. Guided by the crystal structure of the IgV-like domain in the murine TIM-3 extracellular region complexed with a short acyl-chain PS [31], we substituted F40 of TIM-3 (mature human protein numbering) with alanine in one variant (F40A), and replaced both 196 and M97 with alanine in another (I96A/M97A). The corresponding residues in murine TIM-3 (W41/S42, and L99/M100 in PDB entry 3KAA) 'sandwich' the bound PS (Fig. 5A). DeKruyff et al. (2010) showed previously that mutating L99 and M100 of murine TIM-3 greatly impaired PS binding. They also showed that mutating W41 in mTIM-3 abrogated binding, and the W41 sidechain occupies a very similar location to that of the F40 side-chain in hTIM-3 (Figure 5A).

We first used SPR to confirm that these mutations reduce PS binding. Both sTIM- $3^{\mathrm{F} 40 \mathrm{~A}}$ and sTIM-3 $3^{\text {I96A/M97A }}$ displayed substantially reduced PS binding (Figure 5B), reaching only $8 \%$ and $\sim 30 \%$ of saturation respectively at the highest protein concentrations tested. We generated NF- $\kappa$ B reporter Jurkat cells stably-expressing full length TIM-3 variants with these mutations. Having used Western blotting and flow cytometry to confirm that the mutated variants are robustly expressed (Supplementary Figure 2E) and at the cell surface (Supplementary Figure $2 \mathrm{~F}$ ), we assessed NF- $\kappa \mathrm{B}$ signaling and IL-2 secretion after $\alpha \mathrm{CD} 3 / \alpha \mathrm{CD} 28$ stimulation of the 
TCR. Cells expressing the mutated TIM-3 variants showed significantly reduced TCR-induced $\mathrm{NF}-\kappa \mathrm{B}$ activation compared with that seen for cells expressing wild-type TIM-3 (Figures 5C,D). Moreover, cells expressing the mutated variants secreted significantly less IL-2 into their medium compared with cells expressing wild-type TIM-3 (Figure 5E). Similar results were observed when using SEE-loaded Raji B cells to activate the Jurkat cells, where cells expressing mutated variants of TIM-3 produced less IL-2 than wild-type TIM-3-expressing cells (Figure 5F). These results demonstrate that reducing the ability of TIM-3 to bind PS also diminishes its ability to promote TCR signaling, supporting the hypothesis that TIM-3 is engaged with (or saturated by) PS in our Jurkat cell experiments. This in turn argues that PS can promote costimulatory TIM-3 signaling in this T cell model.

\section{A TIM-3 antibody that blocks PS binding also diminishes $\mathbf{T}$ cell signaling}

One concern with such mutational studies is that the mutations might impair TIM-3 function indirectly, through misfolding, for example. We therefore investigated the consequences of blocking PS binding with a TIM-3 antibody. Several TIM-3 antibodies are now in clinical trials in lung cancer and other malignancies [23]. TIM-3 antibodies that have shown efficacy in preclinical studies in mice were all shown to block PS and CEACAM1 (but not galectin-9) binding [34]. The same study also showed that the human TIM-3 monoclonal antibody F38.2E2 blocks PS binding, by interacting with the loops that contain F40 and I96/M97 shown in Figure 5A, and which we mutated for the studies described above. As an orthogonal approach to testing the importance of PS binding for TIM-3 signaling, we explored the effect of F38.2E2 on costimulatory TIM-3 signaling, assessing both NF- $\mathrm{BB}$ activation and IL-2 secretion following TCR stimulation in our Jurkat reporter cell assay. As CEACAM1 is not endogenously expressed in 
Jurkat cells $[66,67]$, any observed effects from F38.2E2 treatment should be specific to blocking the ability of TIM-3 to bind PS.

F38.2E2 addition caused a modest, but significant, dose-dependent decrease in

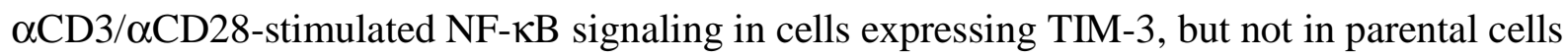
(Figures 6A-E). The effect of F38.2E2 treatment became saturated at approximately $1 \mu \mathrm{g} / \mathrm{ml}$ antibody (Figures 6B,E). Importantly, $10 \mu \mathrm{g} / \mathrm{ml} \mathrm{F38.2E2} \mathrm{also} \mathrm{reduced} \mathrm{(by} \sim 50 \%$ ) the amount of IL-2 secreted by TIM-3 expressing cells upon TCR activation (Figure 6F). Since F38.2E2 is known to block PS binding, these data provide additional support for the argument that TIM-3 engagement by PS is important for its co-stimulatory signaling activity in this system. Inhibition is only partial, but F38.2E2 blocks $\sim 50 \%$ of the TIM-3-dependent increase in NF- $\mathrm{KB}$ signaling or IL-2 secretion, bringing the relative MFI from $\sim 1.0$ to $<0.7$ for TIM-3 cells compared with a value of $\sim 0.35$ for parental cells (compare Figures 6D and E), and reducing IL-2 levels from $\sim 500$ to $\sim 300 \mathrm{pg} / \mathrm{ml}$ (compared with $\sim 40 \mathrm{pg} / \mathrm{ml}$ for parental cells). One possible explanation for the fact that the observed inhibition is partial is that ligands other than PS are also important such as galectin-9, binding of which to TIM-3 is not blocked by F38.2E2. Alternatively, the partial nature of the response could reflect the need for F38.2E2 to compete with a high level of PS on cells in culture, which might be clustered as suggested on activated T cells [56] in a way that enhances its avidity for TIM-3 binding. F38.2E2 antibody treatment itself could also crosslink or cluster TIM-3 in a way that modulates the avidity of TIM-3 for PS, reducing its inhibitory effect. In either case, taken together with the mutational and chimeric receptor studies, our data strongly support a role for extracellular PS binding in regulating TIM-3 co-stimulatory signaling when overexpressed in Jurkat cells, and suggest that inhibition of this signaling is an important component of the function of TIM-3 antibodies currently being studied in the clinic. 


\section{DISCUSSION}

Our findings provide evidence that PS binding to the extracellular region of TIM-3 directly modulates TIM-3 co-signaling activity in a Jurkat T cell model. Consistent with several previous studies, TIM-3 expression in Jurkat cells had a co-stimulatory effect on TCR signaling. We find that this effect requires the intact extracellular region of TIM-3 or another (PS-binding) TIM family member. Moreover, the co-stimulatory effect of TIM-3 is abolished by mutations that impair PS binding - or by treatment with an antibody that occludes the PS-binding site on TIM3. These results argue that PS exposed on the surface of Jurkat cells in culture - which we confirm with annexin V staining - is sufficient to engage TIM-3 and promote its co-stimulatory signaling. The role of PS binding in regulating signaling effects of TIM-3 has remained largely unexplored [8, 68, 69]. PS binding to TIM-3 on macrophages, dendritic cells and fibroblasts has been shown to mediate their phagocytosis of apoptotic cells $[31,32,70]$, whereas the same interaction only allows T cells to form conjugates with apoptotic cells - with no engulfment [31]. Our studies argue that, beyond this coupling function, PS binding to TIM-3 can regulate its activity as a TCR co-signaling receptor.

Several previous studies have reported the presence of a TIM-3 ligand on the surface of various cultured cells, from CD4 T cells $[13,14]$ to fibroblasts to macrophages - and from several different species [55]. The cross-species reactivity observed supports the suggestion that this ligand is PS rather than a protein, and Cao et al. (2007) demonstrated that it is not galectin-9, the most well-studied potential TIM-3 ligand. Together with our results and existing evidence for PS binding by TIM-3 [31-33], it seems likely that most published studies of TIM-3 signaling in culture have been performed with TIM-3 already engaged by a ligand (PS). Nonetheless, the prevailing hypothesis in the field is that galectin-9 is the key TIM-3 ligand and binds TIM-3 to 
trigger co-inhibitory signaling and thus $\mathrm{T}$ cell death $[8,24,71]$. However, as a carbohydratebinding protein, galectin-9 is known to bind numerous other targets [72-75]. Moreover, several studies have argued that some effects of galectin-9 on T cells are TIM-3-independent $[26,75,76]$ or alternatively that galectin-9 does not bind TIM-3 at all [25]. One interesting possibility is that PS is in fact the primary ligand for TIM-3, and that galectin-9 modulates PS binding and/or its consequences.

Alternatively, our findings may suggest that the inhibitory signaling reported for TIM-3 reflects displacement of an activating ligand - namely PS. Galectin-9 could exert its TIM-3dependent effects by pulling TIM-3 into clusters that no longer bind PS, or bind it in a different way. Lee et al. (2011), commented in studies of TIM-3 co-stimulatory signaling that the receptor initially augments $\mathrm{T}$ cell activation, but that rapid inhibition of $\mathrm{T}$ cell activation is seen when TIM-3 is crosslinked with an antibody. Interestingly, that antibody was 5D12, which has subsequently been shown to block PS binding to TIM-3 [34] - so this phenomenon could actually have arisen through reversal of PS stimulation. TIM-3 has also been reported to enhance DC and NK cell activation, as well as FceR1 signaling in mast cells [15, 77, 78]. Moreover, stimulation of TIM-3 with PS was recently reported to promote its phosphorylation in natural killer (NK) cells, leading to inhibition of cytokine secretion [79]. It therefore seems clear that TIM-3 can signal in several different contexts, possibly exerting distinct effects (and effects in different directions) through differential ligand engagement and/or phosphorylation of the tyrosines in its cytoplasmic tail.

Several groups are currently pursuing development of therapeutic antibodies against TIM-3 as a novel immune checkpoint strategy, mostly in combination with PD-1 or PD-L1 antibodies [3, 8, 23]. Identification of the biologically relevant ligand(s) is essential for 
identifying candidate therapies most likely to succeed in the clinic. The findings described here support the importance of PS as a key signaling ligand for TIM-3. Crucially, the epitopes of most functional TIM-3 antibodies have been shown to map to the PS binding site [34, 80] but do not affect galectin-9 binding, arguing that blocking PS binding is key to conferring functional efficacy of the antibodies in promoting immune responses. Most TIM-3 antibodies currently in the clinic block PS binding to the receptor [3], including Sym023 [81], BGB-A425 [82], ICAGN02390 [83], and LY3321367 [84]. Our findings argue that these antibodies most likely block a signaling response to PS binding. Understanding TIM-3 signaling that elicits this response, and the context(s) in which it can be beneficial, will be important for furthering our understanding of this unusual TCR co-signaling receptor, and for understanding potential sideeffects of TIM-3 blockade - which have already been seen in some preclinical contexts [85]. 


\section{DATA AVAILABILITY}

The data needed to evaluate this work are included in the manuscript, and are available upon request.

\section{COMPETEING INTERESTS}

The authors declare no competing interests related to this study.

\section{FUNDING}

This work was supported in part by NIH grant R35-GM122485 (to M.A.L.) and a PhRMA Foundation Predoctoral Fellowship to C.M.S.

\section{AUTHOR CONTRIBUTIONS}

C.M.S. and M.A.L. designed the overall project and wrote the manuscript. C.M.S. performed all experiments and wrote the first manuscript draft. A.L. and N.K. assisted in experiments with TIM-3 chimerae. All authors contributed to analysis of results and manuscript editing.

\section{ACKNOWLEDGEMENTS}

We thank members of the Lemmon and Ferguson laboratories, as well as Aaron Ring and Carla Rothlin for valuable discussions and comments. 


\section{LEGENDS TO FIGURES}

\section{FIGURE 1.}

Ectopic expression of TIM-3 promotes activation of Jurkat cells following stimulation

(A) Flow cytometry analysis of human TIM-3 expression in parental (black) and TIM-3

lentivirus-transduced NF-אB GFP reporter Jurkat cells (red), detected with phycoerythrinconjugated TIM-3 antibody. The inset shows Western blot analysis of TIM-3 expression in the same cells as marked - with three biological repeats of each.

(B) A representative histogram of $\mathrm{NF}-\kappa \mathrm{B}$-driven GFP expression in stimulated $\mathrm{NF}-\kappa \mathrm{B}$ reporter cells (black), and those expressing TIM-3 (red), compared with unstimulated parental (grey) and TIM-3-expressing (pink) cells. Stimulation employed $1 \mu \mathrm{g} / \mathrm{ml} \alpha \mathrm{CD} 3$ plus $1 \mu \mathrm{g} / \mathrm{ml} \alpha \mathrm{CD} 28$ for 16 $\mathrm{h}$ to mimic antigen binding, and $\mathrm{T}$ cell activation was quantified by flow cytometry analysis of the GFP reporter of NFKB transcriptional activity. Enhanced T cell activation in TIM-3expressing cells requires cell stimulation, and no change is observed in unstimulated cells. (C) Mean GFP fluorescence intensity (MFI) values for NF- $\mathrm{BB}$ GFP reporter assays in cells stimulated as in $(\mathbf{B})$ relative to parental NF- $\kappa \mathrm{B}$ reporter cells (black). Data represent averages of 4 biological repeats for TIM-3-expressing cells (red) and two for PD-1-expressing cells (blue). The $\mathrm{p}$ value for the TIM-3/parental comparison was determined with a two-tailed, unpaired Student's t-test.

(D) ELISA analysis of IL-2 secretion into the medium of parental and TIM- $3^{+} \mathrm{NF}-\mathrm{\kappa B}$ reporter cells following stimulation as in $(\mathbf{B})$. Data represent the mean \pm standard deviation (SD) across 3 biological repeats, with p value determined using a two-tailed, unpaired Student's t-test. (E) Production of IL-2 from parental and TIM-3-expressing Jurkat NF- $\mathrm{B} / \mathrm{GFP}$ reporter cells was quantified by ELISA following stimulation by SEE-loaded Raji B cells to mimic formation 
of the immunological synapse during $\mathrm{T}$ cell activation. Data represent mean \pm standard deviation (SD) for 3 biological repeats, with p value determined using a two-tailed, unpaired Student's ttest.

\section{FIGURE 2.}

\section{TIM-3 modulates phosphorylation of CD28 after $\alpha \mathrm{CD} 3 / \alpha \mathrm{CD} 28$ stimulation}

Western blotting was used to monitor changes in phosphorylation of CD28 following TCR activation with $\alpha \mathrm{CD} 3 / \alpha \mathrm{CD} 28$ as in Fig. 1 for $0,5,20$, or $60 \mathrm{~min}$.

(A) Representative Western blot of phospho-CD28 at pY191 for TIM-3-expressing and parental NF- $\kappa B$ reporter Jurkat cells demonstrating elevated phosphorylation of Y191 in TIM-3expressing cells. Grb2 was used as a loading control as described [41]. Quantification bar graphs indicate mean band intensity \pm standard deviation ( $\mathrm{n}=6$ biological repeats). Two-tailed, unpaired Student's t-test was used to determine p values.

(B) Representative Western blot of CD28 phosphorylation at Y218 for TIM- $3^{+}$cells and parental $\mathrm{NF}-\kappa \mathrm{B}$ reporter cells showing elevated phosphorylation at $\mathrm{Y} 218$ at $5 \mathrm{~min}$ in TIM- $3^{+}$cells, with quantitation below the blot. Grb2 was used as a loading control, as above. Bars indicate mean band intensity \pm standard deviation for the 5 min time point ( 7 biological repeats) with p values determined by two-tailed, unpaired Student's t-test.

(C) Parental, TIM-3-expressing, and PD-1-expressing NF- $\kappa \mathrm{B}$ reporter Jurkat cells were stimulated for 5 min with $\alpha \mathrm{CD} 3 / \alpha \mathrm{CD} 28(1 \mu \mathrm{g} / \mathrm{ml}$ each) with- or without the PI3K inhibitor, wortmannin $(0.2 \mu \mathrm{M})$ to show that PTEN deficiency does not account for the effect of TIM-3 expression on CD28 phosphorylation. 


\section{FIGURE 3.}

\section{Chimerae with PS-binding extracellular regions promote T cell signaling}

(A) Schematic depicting PD-1/TIM-3 chimeric constructs. PTT contains the PD-1 extracellular region (ECR) plus transmembrane (TM) and intracellular regions of TIM-3. In PPT, only the intracellular region is replaced with that from TIM-3.

(B) A GFP reporter was used to measure NF- $\kappa \mathrm{B}$ transcriptional activity downstream of TCR activation in parental NF- $\kappa$ B reporter Jurkat cells (black) and the same cells engineered to stably express TIM-3 (red curve), PTT (purple solid curve), PPT (purple dotted curve), or PD-1 (blue curve), stimulated with $1 \mu \mathrm{g} / \mathrm{ml} \alpha \mathrm{CD} 3$ plus $1 \mu \mathrm{g} / \mathrm{ml} \alpha \mathrm{CD} 28$. Representative histograms of NFผB-driven GFP expression are shown.

(C) The relative mean GFP fluorescence intensity (MFI) from 3 biological repeats of the experiment shown in (B) is plotted, expressed as fold change above that measured for parental NF- $\kappa$ B GFP reporter cells. Bars are color coded as in $(\mathbf{B})$ and represent mean MFI value $( \pm$ SD) - with p values determined by two-tailed, unpaired Student's t-test.

(D) Schematic depicting TIM-1/TIM-3 and TIM-4/TIM-3 chimeric constructs in which the TIM3 ECR has been replaced with that of TIM-1 (TIM-1-3) or TIM-4 (TIM-4-3).

(E) Representative histogram of NF- $\mathrm{BB}$-driven GFP expression in parental NF- $\kappa \mathrm{B}$ GFP reporter cells (black), and those expressing TIM-3 (red), TIM-1-3 (teal), or TIM-4-3 (green) following TCR stimulation with $1 \mu \mathrm{g} / \mathrm{ml} \alpha \mathrm{CD} 3$ plus $0.5 \mu \mathrm{g} / \mathrm{ml} \alpha \mathrm{CD} 28$ for $16 \mathrm{~h}$.

(F) Relative mean GFP fluorescence intensity (MFI) values, as fold change above parental cells in each experiment, is plotted for 5 biological repeats of the experiment shown in $(\mathbf{E})$. Bars represent mean $\pm \mathrm{SD}$, with $\mathrm{p}$ values determined by two-tailed, unpaired Student's t-test. 


\section{FIGURE 4.}

\section{The TIM family ligand PS is present on Jurkat cells and binds TIM-3 with low micromolar} affinity

(A) PS exposure on Jurkat cells in culture, detected by staining with fluorescently-tagged

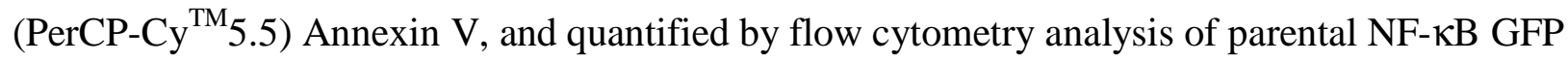
reporter cells (black) and those expressing TIM-3 (red) - compared with unstained cells (grey shaded). A representative histogram from 5 biological repeats is shown.

(B) Fluorescence imaging of parental and TIM-3-expressing NF- $\mathrm{BB}$ GFP reporter cells stained with DAPI (left panels) and fluorescently-tagged (AlexaFluor 647) Annexin V (middle panels). Cells were stained with Annexin V prior to fixation and staining with DAPI.

(C) PS binding of sTIM-1 (teal), sTIM-3 (red), and sTIM-4 (green) was analyzed using SPR by flowing purified TIM ECRs over 20\% DOPS/80\% DOPC lipid vesicles immobilized on an L1 sensorchip. Binding of TIM ECRs was determined in the presence of $1 \mathrm{mM} \mathrm{CaCl}_{2}$. The curves indicate the fit of the data in Prism 8 to a one-site specific binding equation. Binding curves are representative of at least 5 independent experiments. Mean $\mathrm{K}_{\mathrm{d}}$ values and standard deviations are listed in the figure ( $\mathrm{n}=6$ for sTIM-1, $\mathrm{n}=11$ for sTIM-3, and $\mathrm{n}=5$ for sTIM-4). Binding to additional lipids and effects of calcium are shown in Figure S5. 


\section{FIGURE 5.}

\section{Mutated TIM-3 variants with impaired PS binding fail to activate signaling}

(A) Details of the PS binding site in murine TIM-3 (PDB: 3KAA - blue) overlaid on human TIM-3 (PDB: 6TXZ - red), revealing key interacting residues $[31,80]$. Inset at right shows the PS-binding pocket, where short-chain PS is sandwiched by L99/M100 and W41 in mTIM-3 (I96/M97 and F40 in human TIM-3). A calcium ion (grey sphere) also sits in the binding pocket and interacts with the negatively charged PS headgroup.

(B) PS binding of wild-type sTIM-3 (red solid curve), sTIM-3 ${ }^{\text {F40A }}$ (red dotted curve), and sTIM$3^{\text {I96A/M97A }}$ (red dashed curve) were analyzed using SPR by flowing the purified sTIM-3 variants over $20 \%$ DOPS/80\% DOPC lipid vesicles immobilized on an L1 chip (in the presence of $1 \mathrm{mM}$ $\mathrm{CaCl}_{2}$ ). Binding curves are representative of at least 3 independent experiments. $\mathrm{K}_{\mathrm{d}}$ values for sTIM-3 $3^{\text {F40A }}$ and sTIM-3 $3^{\text {I96A/M97A }}$ were too high to measure accurately, both appearing to exceed approximately $200 \mu \mathrm{M}$.

(C) A GFP reporter was used to measure NF- $\kappa$ B transcriptional activity downstream of TCR activation with $1 \mu \mathrm{g} / \mathrm{ml} \alpha \mathrm{CD} 3$ plus $0.5 \mu \mathrm{g} / \mathrm{ml} \alpha \mathrm{CD} 28$ for $16 \mathrm{~h}$. A representative histogram of $\mathrm{NF}-\kappa \mathrm{B}$-driven GFP expression is shown for parental NF- $\kappa \mathrm{B}$ GFP reporter cells (black), and those expressing TIM-3 ${ }^{\mathrm{WT}}$ (red), TIM-3 ${ }^{\mathrm{F} 40 \mathrm{~A}}$ (red dotted), and TIM-3 ${ }^{\text {I96A/M97A }}$ (red dashed) variants.

(D) The relative mean GFP fluorescence intensity (MFI), expressed as fold change from parental cells within each experiment, was determined across 8 biological replicates for parental NF- $\kappa \mathrm{B}$ GFP reporter cells (black) or those expressing TIM $^{\mathrm{WT}}$ (solid red line, open bar), TIM $^{\mathrm{F} 40 \mathrm{~A}}$ (dotted red line, open bar), or TIM ${ }^{\mathrm{I} 96 \mathrm{~A} / \mathrm{M} 97 \mathrm{~A}}$ (dashed red line, grey filled bar). Means \pm SD are plotted, with $\mathrm{p}$ values determined by two-tailed, unpaired Student's t-test. 
(E) ELISA analysis of IL-2 secreted into cell culture medium by parental NF- $\kappa$ B GFP reporter cells, and those expressing, TIM-3 ${ }^{\mathrm{WT}}$ (solid red line, open bar), TIM-3 ${ }^{\mathrm{F} 40 \mathrm{~A}}$ (dotted red line, open bar), or TIM-3 ${ }^{\text {I96A/M97A }}$ (dashed red line, grey filled bar) following stimulation by $\alpha \mathrm{CD} 3 / \alpha \mathrm{CD} 28$, as described in $(\mathbf{C})$. Means \pm SD are plotted for 3 biological repeats. $\mathrm{p}$ values comparing TIM$3^{\mathrm{WT}}$ with the mutated TIM-3 variants were determined using two-tailed, unpaired Student's ttest.

(F) SEE-loaded Raji B cells were used to stimulate NF- $\mathrm{KB}$ GFP reporter Jurkat cells to recapitulate formation of an immunological synapse. IL-2 production following Raji B cell-based activation was determined by IL-2 ELISA analysis for parental NF- $\kappa B$ GFP reporter cells (solid black line, open bar) and cells expressing TIM- $3^{\mathrm{WT}}$ (solid red line, open bar), TIM- $3^{\mathrm{F} 40 \mathrm{~A}}$ (dotted red line, open bar), or TIM-3 $3^{\text {I96A/M97A }}$ (dashed red line, grey filled bar). Mean \pm SD are plotted for 3 biological repeats, with $\mathrm{p}$ values comparing TIM- $3^{\mathrm{WT}}$ with the mutated TIM- 3 variants determined using two-tailed, unpaired Student's t-test. 


\section{FIGURE 6.}

\section{TIM-3 antibody treatment selectively reduces TIM-3 signaling}

(A) Representative histograms of NF- $\kappa \mathrm{B}$-driven GFP expression in parental NF- $\kappa \mathrm{B}$ GFP reporter Jurkat cells were starved for $4 \mathrm{~h}$ - including a $1 \mathrm{~h}$ pre-treatment with anti-TIM3 (F38.2E2) at the concentrations marked - and then stimulated with $1 \mu \mathrm{g} / \mathrm{ml} \alpha \mathrm{CD} 3$ plus $0.5 \mu \mathrm{g} / \mathrm{ml} \alpha \mathrm{CD} 28$ for $16 \mathrm{~h}$ or left unstimulated (grey). GFP expression was analyzed by flow cytometry, and quantitation is shown in (D).

(B) Representative histograms for TIM-3-expressing NF-אB GFP reporter Jurkat cells,

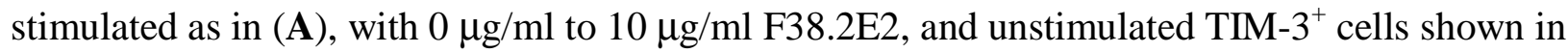
pink. Quantitation is shown in (E).

(C) Representative histograms from TIM-3-expressiong NF- $\mathrm{B}$ GFP reporter Jurkat cells stimulated with $0 \mu \mathrm{g} / \mathrm{ml}$ (red) or $10 \mu \mathrm{g} / \mathrm{ml} \mathrm{F38.2E2} \mathrm{(blue),} \mathrm{showing} \mathrm{that} 10 \mu \mathrm{g} / \mathrm{ml} \mathrm{F38.2E2} \mathrm{does}$ reduce the level of TCR-induced NF- $\mathrm{KB}$-driven GFP expression seen in stimulated TIM-3 cells. (D-E) Quantitation of data in (A) and (C) over 3 independent biological repeats, plotting mean values for relative mean GFP fluorescence intensity (MFI) and standard deviations. $\mathrm{p}$ values were determined with two-tailed, unpaired Student's t-tests.

(F) IL-2 secreted into cell medium was measured by ELISA for parental NF- $\kappa B$ GFP reporter Jurkat cells (black bars) and TIM-3-expressing cells (red bars). Adding $10 \mu \mathrm{g} / \mathrm{ml} \mathrm{F38.2E2}$ reduces enhanced IL-2 production in TIM-3 expressing cells. Bars represent mean concentration of IL-2 ( \pm SD) for 3 biological replicates. p values were determined with two-tailed, unpaired Student's t-tests. 


\section{REFERENCES}

1 Chen, L. and Flies, D.B. (2013) Molecular mechanisms of T cell co-stimulation and coinhibition. Nat. Rev. Immunol. 13, 227-242 https://doi.org/10.1038/nri3405

2 Edner, N.M., Carlesso, G., Rush, J.S. and Walker, L.S.K. (2020) Targeting co-stimulatory molecules in autoimmune disease. Nat. Rev. Drug Discov., Sep 16 https://doi.org/10.1038/s41573-020-0081-9

3 Andrews, L.P., Yano, H. and Vignali, D.A.A. (2019) Inhibitory receptors and ligands beyond PD-1, PD-L1 and CTLA-4: breakthroughs or backups. Nat. Immunol. 20, 1425-1434 https://doi.org/10.1038/s41590-019-0512-0

4 Topalian, S.L., Taube, J.M. and Pardoll, D.M. (2020) Neoadjuvant checkpoint blockade for cancer immunotherapy. Science 367, eaax0182 https://doi.org/10.1126/science.aax0182

5 Ogawa, S. and Abe, R. (2019) Signal transduction via co-stimulatory and co-inhibitory receptors. Adv. Exp. Med. Biol. 1189, 85-133 https://doi.org/10.1007/978-981-32-9717-3_4

6 Avery, L., Filderman, J., Szymczak-Workman, A.L. and Kane, L.P. (2018) Tim-3 costimulation promotes short-lived effector T cells, restricts memory precursors, and is dispensable for T cell exhaustion. Proc. Natl. Acad. Sci. U S A 115, 2455-2460 https://doi.org/10.1073/pnas.1712107115

7 Ferris, R.L., Lu, B. and Kane, L.P. (2014) Too much of a good thing? Tim-3 and TCR signaling in T cell exhaustion. J. Immunol. 193, 1525-1530 https://doi.org/10.4049/jimmunol.1400557

8 Wolf, Y., Anderson, A.C. and Kuchroo, V.K. (2020) TIM3 comes of age as an inhibitory receptor. Nat. Rev. Immunol. 20, 173-185 https://doi.org/10.1038/s41577-019-0224-6

9 Monney, L., Sabatos, C.A., Gaglia, J.L., Ryu, A., Waldner, H., Chernova, T., Manning, S., Greenfield, E.A., Coyle, A.J., Sobel, R.A., Freeman, G.J. and Kuchroo, V.K. (2002) Th1specific cell surface protein Tim-3 regulates macrophage activation and severity of an autoimmune disease. Nature 415, 536-541 https://doi.org/10.1038/415536a

10 Jin, H.T., Anderson, A.C., Tan, W.G., West, E.E., Ha, S.J., Araki, K., Freeman, G.J., Kuchroo, V.K. and Ahmed, R. (2010) Cooperation of Tim-3 and PD-1 in CD8 T-cell exhaustion during chronic viral infection. Proc. Natl. Acad. Sci. U S A 107, 14733-14738 https://doi.org/10.1073/pnas.1009731107

11 Jones, R.B., Ndhlovu, L.C., Barbour, J.D., Sheth, P.M., Jha, A.R., Long, B.R., Wong, J.C., Satkunarajah, M., Schweneker, M., Chapman, J.M., Gyenes, G., Vali, B., Hyrcza, M.D., Yue, F.Y., Kovacs, C., Sassi, A., Loutfy, M., Halpenny, R., Persad, D., Spotts, G., Hecht, F.M., Chun, T.W., McCune, J.M., Kaul, R., Rini, J.M., Nixon, D.F. and Ostrowski, M.A. (2008) Tim-3 expression defines a novel population of dysfunctional T cells with highly elevated frequencies in progressive HIV-1 infection. J. Exp. Med. 205, 2763-2779 https://doi.org/10.1084/jem.20081398 
12 Zhou, Q., Munger, M.E., Veenstra, R.G., Weigel, B.J., Hirashima, M., Munn, D.H., Murphy, W.J., Azuma, M., Anderson, A.C., Kuchroo, V.K. and Blazar, B.R. (2011) Coexpression of Tim-3 and PD-1 identifies a CD8+ T-cell exhaustion phenotype in mice with disseminated acute myelogenous leukemia. Blood 117, 4501-4510 https://doi.org/10.1182/blood-2010-10$\underline{310425}$

13 Sabatos, C.A., Chakravarti, S., Cha, E., Schubart, A., Sanchez-Fueyo, A., Zheng, X.X., Coyle, A.J., Strom, T.B., Freeman, G.J. and Kuchroo, V.K. (2003) Interaction of Tim-3 and Tim-3 ligand regulates T helper type 1 responses and induction of peripheral tolerance. Nat. Immunol. 4, 1102-1110 https://doi.org/10.1038/ni988

14 Sanchez-Fueyo, A., Tian, J., Picarella, D., Domenig, C., Zheng, X.X., Sabatos, C.A., Manlongat, N., Bender, O., Kamradt, T., Kuchroo, V.K., Gutierrez-Ramos, J.C., Coyle, A.J. and Strom, T.B. (2003) Tim-3 inhibits T helper type 1-mediated auto- and alloimmune responses and promotes immunological tolerance. Nat Immunol 4, 1093-1101 https://doi.org/10.1038/ni987

15 Anderson, A.C., Anderson, D.E., Bregoli, L., Hastings, W.D., Kassam, N., Lei, C., Chandwaskar, R., Karman, J., Su, E.W., Hirashima, M., Bruce, J.N., Kane, L.P., Kuchroo, V.K. and Hafler, D.A. (2007) Promotion of tissue inflammation by the immune receptor Tim-3 expressed on innate immune cells. Science 318, 1141-1143 https://doi.org/10.1126/science.1148536

16 Gorman, J.V., Starbeck-Miller, G., Pham, N.L., Traver, G.L., Rothman, P.B., Harty, J.T. and Colgan, J.D. (2014) Tim-3 directly enhances CD8 T cell responses to acute Listeria monocytogenes infection. J. Immunol. 192, 3133-3142 https://doi.org/10.4049/jimmunol.1302290

17 Lee, J., Su, E.W., Zhu, C., Hainline, S., Phuah, J., Moroco, J.A., Smithgall, T.E., Kuchroo, V.K. and Kane, L.P. (2011) Phosphotyrosine-dependent coupling of Tim-3 to T-cell receptor signaling pathways. Mol. Cell. Biol. 31, 3963-3974 https://doi.org/10.1128/MCB.05297-11

18 Lee, M.J., Woo, M.Y., Chwae, Y.J., Kwon, M.H., Kim, K. and Park, S. (2012) Downregulation of interleukin-2 production by CD4(+) T cells expressing TIM-3 through suppression of NFAT dephosphorylation and AP-1 transcription. Immunobiology 217, 986995 https://doi.org/10.1016/j.imbio.2012.01.012

19 Tomkowicz, B., Walsh, E., Cotty, A., Verona, R., Sabins, N., Kaplan, F., Santulli-Marotto, S., Chin, C.N., Mooney, J., Lingham, R.B., Naso, M. and McCabe, T. (2015) TIM-3 suppresses anti-CD3/CD28-induced TCR activation and IL-2 expression through the NFAT signaling pathway. PLoS One 10, e0140694 https://doi.org/10.1371/journal.pone.0140694

20 Daëron, M., Jaeger, S., Du Pasquier, L. and Vivier, E. (2008) Immunoreceptor tyrosine-based inhibition motifs: a quest in the past and future. Immunol. Rev. 224, 11-43 https://doi.org/10.1111/j.1600-065X.2008.00666.X

21 Fourcade, J., Sun, Z., Benallaoua, M., Guillaume, P., Luescher, I.F., Sander, C., Kirkwood, J.M., Kuchroo, V. and Zarour, H.M. (2010) Upregulation of Tim-3 and PD-1 expression is 
associated with tumor antigen-specific CD8+ T cell dysfunction in melanoma patients. $J$. Exp. Med. 207, 2175-2186 https://doi.org/10.1084/jem.20100637

22 Sakuishi, K., Apetoh, L., Sullivan, J.M., Blazar, B.R., Kuchroo, V.K. and Anderson, A.C. (2010) Targeting Tim-3 and PD-1 pathways to reverse T cell exhaustion and restore antitumor immunity. J. Exp. Med. 207, 2187-2194 https://doi.org/10.1084/jem.20100643

23 Acharya, N., Sabatos-Peyton, C. and Anderson, A.C. (2020) Tim-3 finds its place in the cancer immunotherapy landscape. J. Immunother. Cancer 8, e000911 https://doi.org/10.1136/jitc-2020-000911

24 Zhu, C., Anderson, A.C., Schubart, A., Xiong, H., Imitola, J., Khoury, S.J., Zheng, X.X., Strom, T.B. and Kuchroo, V.K. (2005) The Tim-3 ligand galectin-9 negatively regulates T helper type 1 immunity. Nat. Immunol. 6, 1245-1252 https://doi.org/10.1038/ni1271

25 Leitner, J., Rieger, A., Pickl, W.F., Zlabinger, G., Grabmeier-Pfistershammer, K. and Steinberger, P. (2013) TIM-3 does not act as a receptor for galectin-9. PLoS Pathog. 9, e1003253 https://doi.org/10.1371/journal.ppat.1003253

$26 \mathrm{Su}$, E.W., Bi, S. and Kane, L.P. (2011) Galectin-9 regulates T helper cell function independently of Tim-3. Glycobiology 21, 1258-1265 https://doi.org/10.1093/glycob/cwq214

27 Leventis, P.A. and Grinstein, S. (2010) The distribution and function of phosphatidylserine in cellular membranes. Annu. Rev. Biophys. 39, 407-427

https://doi.org/10.1146/annurev.biophys.093008.131234

28 Shlomovitz, I., Speir, M. and Gerlic, M. (2019) Flipping the dogma - phosphatidylserine in non-apoptotic cell death. Cell Commun. Signal. 17, 139 https://doi.org/10.1186/s12964-019$\underline{0437-0}$

29 Fischer, K., Voelk1, S., Berger, J., Andreesen, R., Pomorski, T. and Mackensen, A. (2006) Antigen recognition induces phosphatidylserine exposure on the cell surface of human CD8+ T cells. Blood 108, 4094-4101 https://doi.org/10.1182/blood-2006-03-011742

30 Miyanishi, M., Tada, K., Koike, M., Uchiyama, Y., Kitamura, T. and Nagata, S. (2007) Identification of Tim4 as a phosphatidylserine receptor. Nature 450, 435-439 https://doi.org/10.1038/nature06307

31 DeKruyff, R.H., Bu, X., Ballesteros, A., Santiago, C., Chim, Y.L., Lee, H.H., Karisola, P., Pichavant, M., Kaplan, G.G., Umetsu, D.T., Freeman, G.J. and Casasnovas, J.M. (2010) T cell/transmembrane, Ig, and mucin-3 allelic variants differentially recognize phosphatidylserine and mediate phagocytosis of apoptotic cells. J. Immunol. 184, 1918-1930 https://doi.org/10.4049/jimmunol.0903059

32 Nakayama, M., Akiba, H., Takeda, K., Kojima, Y., Hashiguchi, M., Azuma, M., Yagita, H. and Okumura, K. (2009) Tim-3 mediates phagocytosis of apoptotic cells and crosspresentation. Blood 113, 3821-3830 https://doi.org/10.1182/blood-2008-10-185884 
33 Tietjen, G.T., Gong, Z., Chen, C.H., Vargas, E., Crooks, J.E., Cao, K.D., Heffern, C.T., Henderson, J.M., Meron, M., Lin, B., Roux, B., Schlossman, M.L., Steck, T.L., Lee, K.Y. and Adams, E.J. (2014) Molecular mechanism for differential recognition of membrane phosphatidylserine by the immune regulatory receptor Tim4. Proc. Natl. Acad. Sci. U S A 111, E1463-1472 https://doi.org/10.1073/pnas.1320174111

34 Sabatos-Peyton, C.A., Nevin, J., Brock, A., Venable, J.D., Tan, D.J., Kassam, N., Xu, F., Taraszka, J., Wesemann, L., Pertel, T., Acharya, N., Klapholz, M., Etminan, Y., Jiang, X., Huang, Y.H., Blumberg, R.S., Kuchroo, V.K. and Anderson, A.C. (2018) Blockade of Tim-3 binding to phosphatidylserine and CEACAM1 is a shared feature of anti-Tim-3 antibodies that have functional efficacy. Oncoimmunology 7, e1385690 https://doi.org/10.1080/2162402X.2017.1385690

35 Gibson, D.G. (2011) Enzymatic assembly of overlapping DNA fragments. Meth. Enzymol. 498, 349-361 https://doi.org/10.1016/B978-0-12-385120-8.00015-2

36 Seiler, C.Y., Park, J.G., Sharma, A., Hunter, P., Surapaneni, P., Sedillo, C., Field, J., Algar, R., Price, A., Steel, J., Throop, A., Fiacco, M. and LaBaer, J. (2014) DNASU plasmid and PSI:Biology-Materials repositories: resources to accelerate biological research. $\mathrm{Nucl}$. Acids Res. 42, D1253-D1260 https://doi.org/10.1093/nar/gkt1060

37 Muzumdar, M.D., Chen, P.Y., Dorans, K.J., Chung, K.M., Bhutkar, A., Hong, E., Noll, E.M., Sprick, M.R., Trumpp, A. and Jacks, T. (2017) Survival of pancreatic cancer cells lacking KRAS function. Nat. Commun. 8, 1090 https://doi.org/10.1038/s41467-017-00942-5

38 O'Doherty, U., Swiggard, W.J. and Malim, M.H. (2000) Human immunodeficiency virus type 1 spinoculation enhances infection through virus binding. J. Virol. 74, 10074-10080 https://doi.org/10.1128/jvi.74.21.10074-10080.2000

39 Mujib, S., Jones, R.B., Lo, C., Aidarus, N., Clayton, K., Sakhdari, A., Benko, E., Kovacs, C. and Ostrowski, M.A. (2012) Antigen-independent induction of Tim-3 expression on human T cells by the common $\gamma$-chain cytokines IL-2, IL-7, IL-15, and IL-21 is associated with proliferation and is dependent on the phosphoinositide 3-kinase pathway. J. Immunol. 188, 3745-3756 https://doi.org/10.4049/jimmunol.1102609

40 Xu, X., Hou, B., Fulzele, A., Masubuchi, T., Zhao, Y., Wu, Z., Hu, Y., Jiang, Y., Ma, Y., Wang, H., Bennett, E.J., Fu, G. and Hui, E. (2020) PD-1 and BTLA regulate T cell signaling differentially and only partially through SHP1 and SHP2. J. Cell Biol. 219, e201905085 https://doi.org/10.1083/jcb.201905085

41 Aksamitiene, E., Hoek, J.B. and Kiyatkin, A. (2015) Multistrip Western blotting: a tool for comparative quantitative analysis of multiple proteins. Methods Mol. Biol. 1312, 197-226 https://doi.org/10.1007/978-1-4939-2694-7 23

42 Moravcevic, K., Mendrola, J.M., Schmitz, K.R., Wang, Y.H., Slochower, D., Janmey, P.A. and Lemmon, M.A. (2010) Kinase associated-1 domains drive MARK/PAR1 kinases to membrane targets by binding acidic phospholipids. Cell 143, 966-977 https://doi.org/10.1016/j.cell.2010.11.028 
43 Narayan, K. and Lemmon, M.A. (2006) Determining selectivity of phosphoinositide-binding domains. Methods 39, 122-133 https://doi.org/10.1016/j.ymeth.2006.05.006

44 Moorman, J.P., Wang, J.M., Zhang, Y., Ji, X.J., Ma, C.J., Wu, X.Y., Jia, Z.S., Wang, K.S. and Yao, Z.Q. (2012) Tim-3 pathway controls regulatory and effector T cell balance during hepatitis $\mathrm{C}$ virus infection. J. Immunol. 189, 755-766 https://doi.org/10.4049/jimmunol.1200162

45 Abraham, R.T. and Weiss, A. (2004) Jurkat T cells and development of the T-cell receptor signalling paradigm. Nat. Rev. Immunol. 4, 301-308 https://doi.org/10.1038/nri1330

46 Hayden, M.S., West, A.P. and Ghosh, S. (2006) NF-kappaB and the immune response. Oncogene 25, 6758-6780 https://doi.org/10.1038/sj.onc.1209943

47 Kataoka, S., Manandhar, P., Workman, C.J., Banerjee, H., Szymczak-Workman, A.L., Kvorjak, M., Lohmueller, J. and Kane, L.P. (2020) The co-stimulatory activity of Tim-3 requires Akt and MAPK signaling and immune synapse recruitment. bioRxivhttps://doi.org/10.1101/2019.12.30.878520

48 Boomer, J.S. and Green, J.M. (2010) An enigmatic tail of CD28 signaling. Cold Spring Harb. Perspect. Biol. 2, a002436 https://doi.org/10.1101/cshperspect.a002436

49 Cook, J.A., Albacker, L., August, A. and Henderson, A.J. (2003) CD28-dependent HIV-1 transcription is associated with Vav, Rac, and NF-kappa B activation. J. Biol. Chem. 278, 35812-35818 https://doi.org/10.1074/jbc.M302878200

50 Teng, J.M., King, P.D., Sadra, A., Liu, X., Han, A., Selvakumar, A., August, A. and Dupont, B. (1996) Phosphorylation of each of the distal three tyrosines of the CD28 cytoplasmic tail is required for CD28-induced T cell IL-2 secretion. Tissue Antigens 48https://doi.org/10.1111/j.1399-0039.1996.tb02643.X

51 Prasad, K.V., Cai, Y.C., Raab, M., Duckworth, B., Cantley, L., Shoelson, S.E. and Rudd, C.E. (1994) T-cell antigen CD28 interacts with the lipid kinase phosphatidylinositol 3-kinase by a cytoplasmic Tyr(P)-Met-Xaa-Met motif. Proc. Natl. Acad. Sci. U S A 91, 2834-2838 https://doi.org/10.1073/pnas.91.7.2834

52 Pagès, F., Ragueneau, M., Rottapel, R., Truneh, A., Nunes, J., Imbert, J. and Olive, D. (1994) Binding of phosphatidylinositol-3-OH kinase to CD28 is required for T-cell signalling. Nature 369, 327-329 https://doi.org/10.1038/369327a0

53 Shan, X., Czar, M.J., Bunnell, S.C., Liu, P., Liu, Y., Schwartzberg, P.L. and Wange, R.L. (2000) Deficiency of PTEN in Jurkat T cells causes constitutive localization of Itk to the plasma membrane and hyperresponsiveness to CD3 stimulation. Mol. Cell. Biol.. 20, 69456957 https://doi.org/10.1128/mcb.20.18.6945-6957.2000

54 Rodriguez-Manzanet, R., DeKruyff, R., Kuchroo, V.K. and Umetsu, D.T. (2009) The costimulatory role of TIM molecules. Immunol. Rev. 229, 259-270 https://doi.org/10.1111/j.1600-065X.2009.00772.x 
55 Cao, E., Zang, X., Ramagopal, U.A., Mukhopadhaya, A., Fedorov, A., Fedorov, E., Zencheck, W.D., Lary, J.W., Cole, J.L., Deng, H., Xiao, H., Dilorenzo, T.P., Allison, J.P., Nathenson, S.G. and Almo, S.C. (2007) T cell immunoglobulin mucin-3 crystal structure reveals a galectin-9-independent ligand-binding surface. Immunity 26, 311-321 https://doi.org/10.1016/j.immuni.2007.01.016

56 Fischer, K., Voelkl, S., Berger, J., Andreesen, R., Pomorski, T. and Mackensen, A. (2006) Antigen recognition induces phosphatidylserine exposure on the cell surface of human CD8+ T cells. Blood 108, 4094-4101 https://doi.org/10.1182/blood-2006-03-011742

57 Lemke, G. (2017) Phosphatidylserine is the signal for TAM receptors and their ligands. Trends Biochem. Sci. 42, 738-748 https://doi.org/10.1016/j.tibs.2017.06.004

58 Heinrich, L., Tissot, N., Hartmann, D.J. and Cohen, R. (2010) Comparison of the results obtained by ELISA and surface plasmon resonance for the determination of antibody affinity. J. Immunol. Meth. 352, 13-22 https://doi.org/10.1016/j.jim.2009.10.002

59 Lemmon, M.A. (2008) Membrane recognition by phospholipid-binding domains. Nat. Rev. Mol. Cell. Biol. 9, 99-111 https://doi.org/10.1038/nrm2328

60 Yeung, T., Gilbert, G.E., Shi, J., Silvius, J., Kapus, A. and Grinstein, S. (2008) Membrane phosphatidylserine regulates surface charge and protein localization. Science 319, 210-213 https://doi.org/10.1126/science.1152066

61 Sansom, D.M. (2000) CD28, CTLA-4 and their ligands: who does what and to whom? Immunology 101, 169-177 https://doi.org/10.1046/j.1365-2567.2000.00121.X

62 Zak, K.M., Grudnik, P., Magiera, K., Dömling, A., Dubin, G. and Holak, T.A. (2017) Structural biology of the immune checkpoint receptor PD-1 and its ligands PD-L1/PD-L2. Structure 25, 1163-1174 https://doi.org/10.1016/j.str.2017.06.011

63 Baxter, A.A., Hulett, M.D. and Poon, I.K. (2015) The phospholipid code: a key component of dying cell recognition, tumor progression and host-microbe interactions. Cell Death Differ. 22, 1893-1905 https://doi.org/10.1038/cdd.2015.122

64 Emoto, K., Toyama-Sorimachi, N., Karasuyama, H., Inoue, K. and Umeda, M. (1997) Exposure of phosphatidylethanolamine on the surface of apoptotic cells. Exp. Cell Res. 232, 430-434 https://doi.org/10.1006/excr.1997.3521

65 Richard, A.S., Zhang, A., Park, S.J., Farzan, M., Zong, M. and Choe, H. (2015) Virionassociated phosphatidylethanolamine promotes TIM1-mediated infection by Ebola, dengue, and West Nile viruses. Proc. Natl. Acad. Sci. U S A 112, 14682-14687 https://doi.org/10.1073/pnas.1508095112

66 Chen, D., Iijima, H., Nagaishi, T., Nakajima, A., Russell, S., Raychowdhury, R., Morales, V., Rudd, C.E., Utku, N. and Blumberg, R.S. (2004) Carcinoembryonic antigen-related cellular adhesion molecule 1 isoforms alternatively inhibit and costimulate human T cell function. $J$. Immunol. 172, 3535-3543 https://doi.org/10.4049/jimmunol.172.6.3535 
67 Donda, A., Mori, L., Shamshiev, A., Carena, I., Mottet, C., Heim, M.H., Beglinger, C., Grunert, F., Rochlitz, C., Terracciano, L., Jantscheff, P. and De Libero, G. (2000) Locally inducible CD66a (CEACAM1) as an amplifier of the human intestinal T cell response. Eur. J. Immunol. 30, 2593-2603 https://doi.org/10.1002/1521-4141(200009)30:9<2593::AIDIMMU2593>3.0.CO;2-0

68 Dayoub, A.S. and Brekken, R.A. (2020) TIMs, TAMs, and PS- antibody targeting: implications for cancer immunotherapy. Cell Commun. Signal. 18, 29 https://doi.org/10.1186/s12964-020-0521-5

69 Freeman, G.J., Casasnovas, J.M., Umetsu, D.T. and DeKruyff, R.H. (2010) TIM genes: a family of cell surface phosphatidylserine receptors that regulate innate and adaptive immunity. Immunol. Rev. 235, 172-189 https://doi.org/10.1111/j.0105-2896.2010.00903.x

70 Zhao, D., Guo, M., Liu, B., Lin, Q., Xie, T., Zhang, Q., Jia, X., Shu, Q., Liang, X., Gao, L. and Ma, C. (2017) Frontline Science: Tim-3-mediated dysfunctional engulfment of apoptotic cells in SLE. J. Leukoc. Biol. 102, 1313-1322 https://doi.org/10.1189/jlb.3HI0117-005RR

71 Zhu, C., Anderson, A.C. and Kuchroo, V.K. (2011) TIM-3 and its regulatory role in immune responses. Curr. Top. Microbiol. Immunol. 350, 1-15 https://doi.org/10.1007/82 201084

72 Niki, T., Tsutsui, S., Hirose, S., Aradono, S., Sugimoto, Y., Takeshita, K., Nishi, N. and Hirashima, M. (2009) Galectin-9 is a high affinity IgE-binding lectin with anti-allergic effect by blocking IgE-antigen complex formation. J. Biol. Chem. 284, 32344-32352 https://doi.org/10.1074/jbc.M109.035196

73 Bi, S., Hong, P.W., Lee, B. and Baum, L.G. (2011) Galectin-9 binding to cell surface protein disulfide isomerase regulates the redox environment to enhance T-cell migration and HIV entry. Proc. Natl. Acad. Sci. U S A 108, 10650-10655

https://doi.org/10.1073/pnas.1017954108

74 Cao, A., Alluqmani, N., Buhari, F.H.M., Wasim, L., Smith, L.K., Quaile, A.T., Shannon, M., Hakim, Z., Furmli, H., Owen, D.M., Savchenko, A. and Treanor, B. (2018) Galectin-9 binds IgM-BCR to regulate B cell signaling. Nat. Commun. 9, 3288 https://doi.org/10.1038/s41467-018-05771-8

75 Wu, C., Thalhamer, T., Franca, R.F., Xiao, S., Wang, C., Hotta, C., Zhu, C., Hirashima, M., Anderson, A.C. and Kuchroo, V.K. (2014) Galectin-9-CD44 interaction enhances stability and function of adaptive regulatory T cells. Immunity 41, 270-282

https://doi.org/10.1016/j.immuni.2014.06.011

76 Oomizu, S., Arikawa, T., Niki, T., Kadowaki, T., Ueno, M., Nishi, N., Yamauchi, A. and Hirashima, M. (2012) Galectin-9 suppresses Th17 cell development in an IL-2-dependent but Tim-3-independent manner. Clin. Immunol. 143, 51-58 https://doi.org/10.1016/j.clim.2012.01.004.

77 Gleason, M.K., Lenvik, T.R., McCullar, V., Felices, M., O'Brien, M.S., Cooley, S.A., Verneris, M.R., Cichocki, F., Holman, C.J., Panoskaltsis-Mortari, A., Niki, T., Hirashima, 
M., Blazar, B.R. and Miller, J.S. (2012) Tim-3 is an inducible human natural killer cell receptor that enhances interferon gamma production in response to galectin-9. Blood 119, 3064-3072 https://doi.org/10.1182/blood-2011-06-360321

78 Phong, B.L., Avery, L., Sumpter, T.L., Gorman, J.V., Watkins, S.C., Colgan, J.D. and Kane, L.P. (2015) Tim-3 enhances FceRI-proximal signaling to modulate mast cell activation. $J$. Exp. Med. 212, 2289-2304 https://doi.org/10.1084/jem.20150388

79 Tan, S., Xu, Y., Wang, Z., Wang, T., Du, X., Song, X., Guo, X., Peng, J., Zhang, J., Liang, Y., Lu, J., Peng, J., Gao, C., Wu, Z., Li, C., Li, N., Gao, L., Liang, X. and Ma, C. (2020) Tim-3 hampers tumor surveillance of liver-resident and conventional NK cells by disrupting PI3K signaling. Cancer Res. 80, 1130-1142 https://doi.org/10.1158/0008-5472.CAN-19$\underline{2332}$

80 Zhang, D., Jiang, F., Zaynagetdinov, R., Huang, H., Sood, V.D., Wang, H., Zhao, X., Jenkins, M.H., Ji, Q., Wang, Y., Nannemann, D.P., Musil, D., Wesolowski, J., Paoletti, A., Bartholomew, T., Derner, M.G., An, Q., Iffland, C. and Halle, J.P. (2020) Identification and characterization of M6903, an antagonistic anti-TIM-3 monoclonal antibody. Oncoimmunology 9, 1744921 https://doi.org/10.1080/2162402X.2020.1744921

81 Lindsted, T., Gad, M., Grandal, M.V., Frölich, C., Bhatia, V.K., Gjetting, T., Lantto, J., Horak, I.D., Kragh, M., Koefoed, K. and Pedersen, M.W. (2018) Abstract 5629: Preclinical characterization of Sym023 a human anti-TIM3 antibody with a novel mechanism of action. Cancer Res. 78, 5629-5629 https://doi.org/10.1158/1538-7445.Am2018-5629

82 Zhang, T., Xue, L., Zhang, J., Liu, Q., Ma, J., Zhang, Y., Shi, Y., Hou, H., Peng, H., Liu, N., Zhang, Y., Song, X., Li, Y., Song, J., Wang, L., Wei, M. and Li, K. (2017) Abstract 2628: BGB-A425: a humanized anti-human Tim-3 antibody that exhibits strong immune cell activation. Cancer Res. 77, 2628-2628 https://doi.org/10.1158/1538-7445.Am2017-2628

83 Waight, J., Iyer, P., Breous-Nystrom, E., Riordan, C., Findeis, M., Underwood, D., Connolly, J., Sanicola-Nadel, M., Nastri, H., Scherle, P., Hollis, G., Huber, R., Stein, R., Dijk, M.v. and Wilson, N.S. (2018) Abstract 3825: INCAGN02390, a novel antagonist antibody that targets the co-inhibitory receptor TIM-3. Cancer Res. 78, 3825-3825 https://doi.org/10.1158/15387445.Am2018-3825

84 Haidar, J.N., Antonysamy, S., Mathew, S., Wu, L., Zhang, Y., Kearins, M.C., Shen, L., Sauder, J.M., Schaer, D., Driscoll, K.E. and Kalos, M. (2019) Abstract 2753: The molecular basis of blocking the TIM-3 checkpoint with the LY3321367 mAb in cancer immunotherapy. Cancer Res. 79, 2753-2753 https://doi.org/10.1158/1538-7445.Am2019-2753

85 Isshiki, T., Akiba, H., Nakayama, M., Harada, N., Okumura, K., Homma, S. and Miyake, S. (2017) Cutting edge: Anti-TIM-3 treatment exacerbates pulmonary inflammation and fibrosis in mice. J. Immunol. 199, 3733-3737 https://doi.org/10.4049/jimmunol.1700059 
A

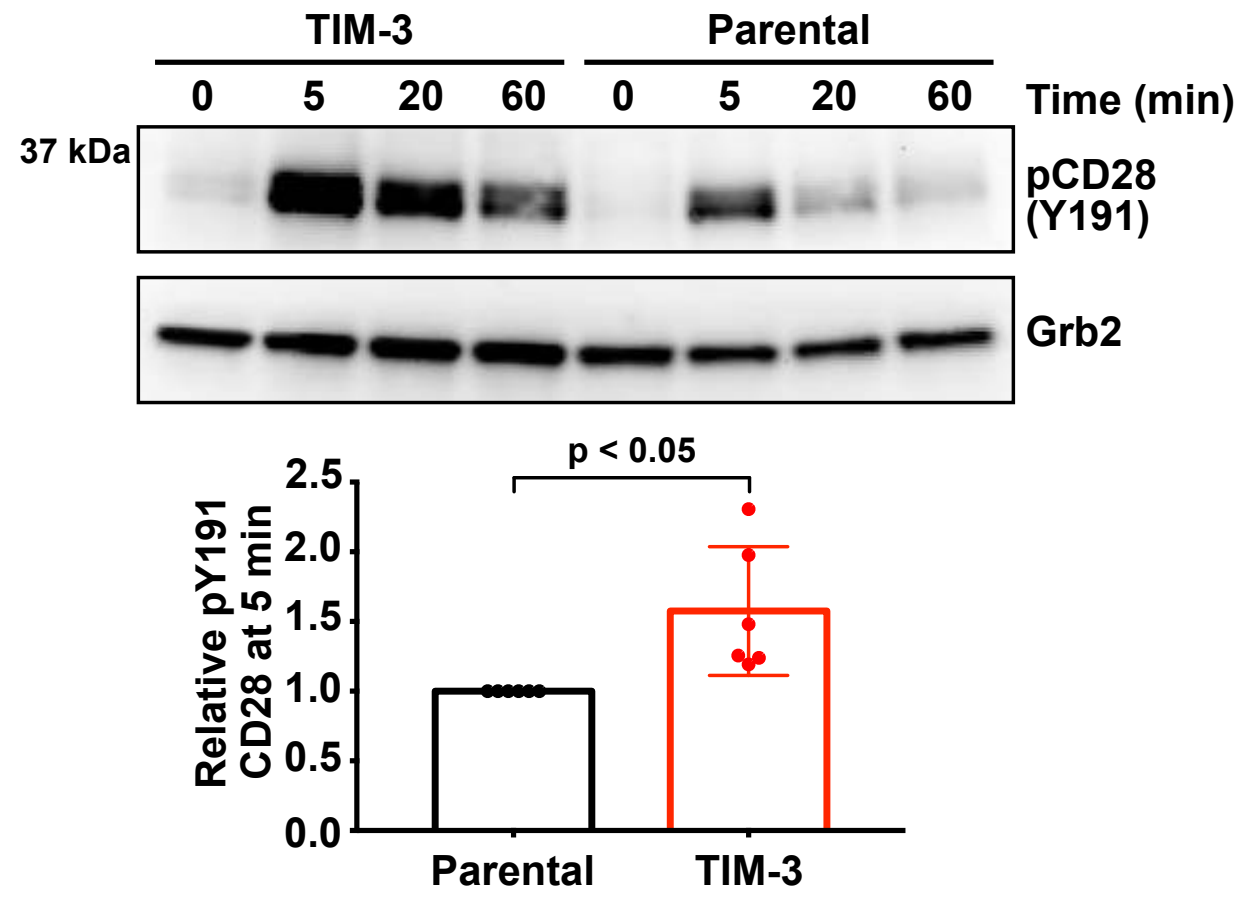

B
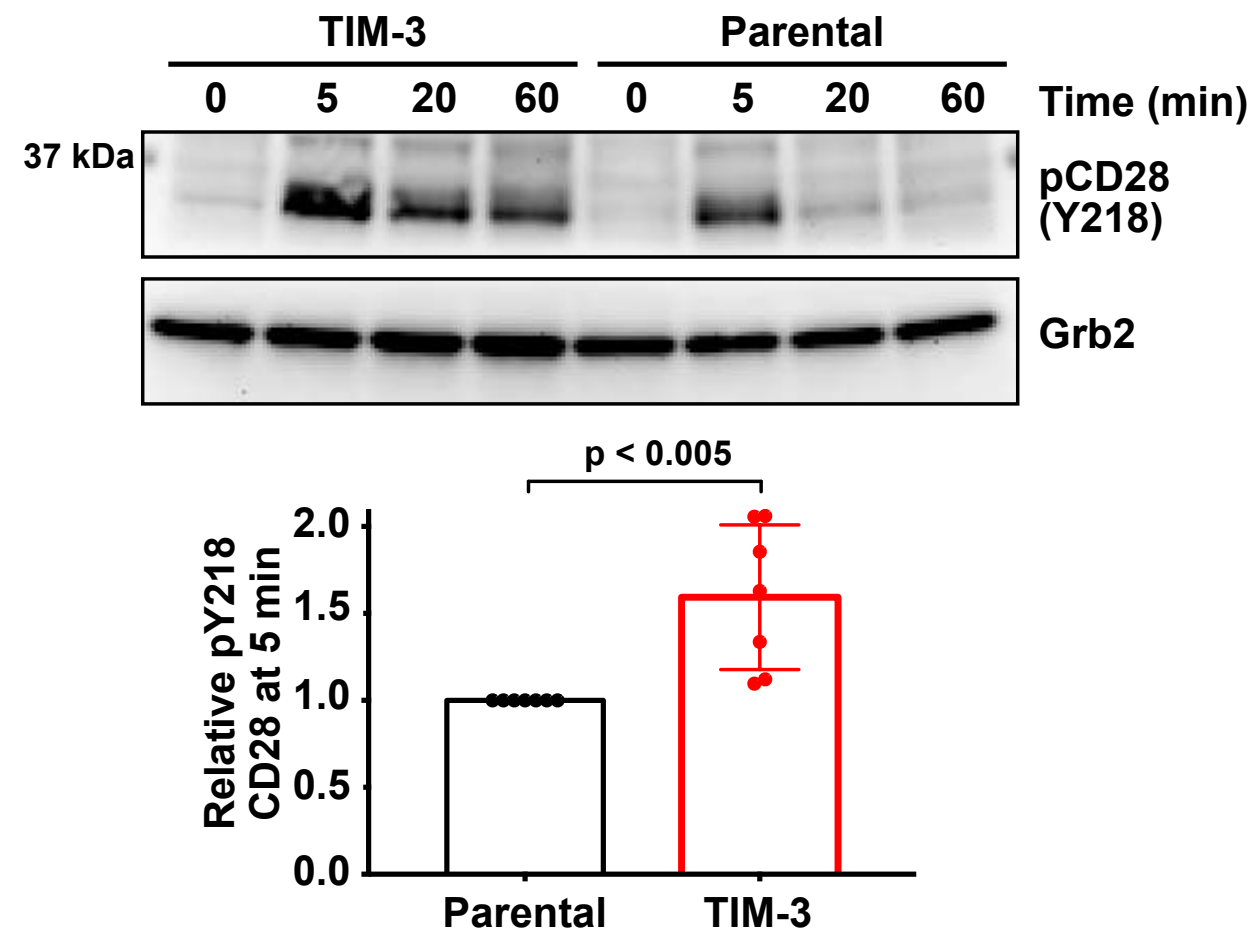

C

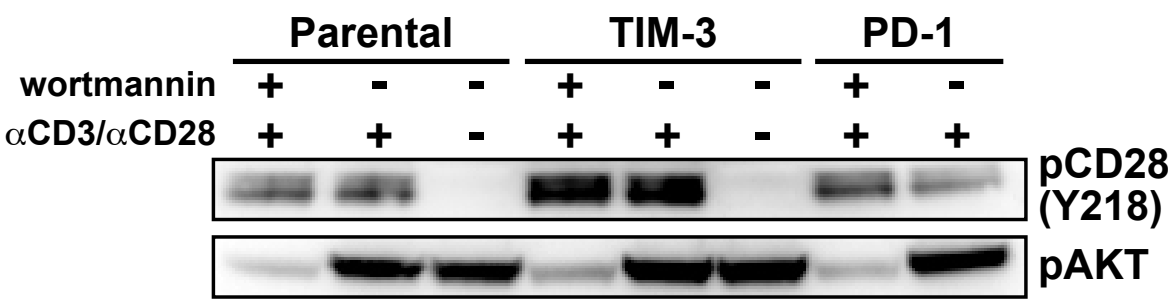

Figure 2 
A

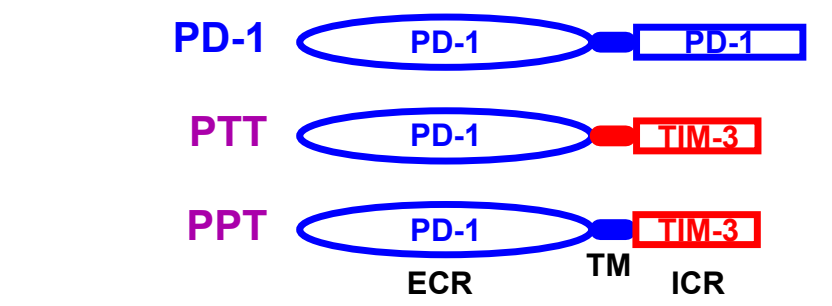

\section{D}

B

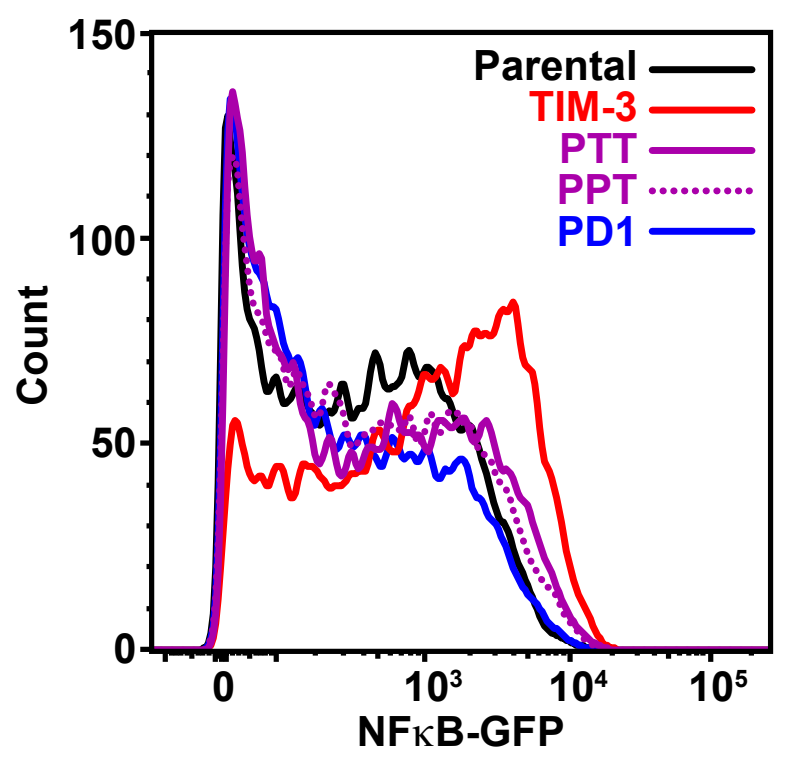

0

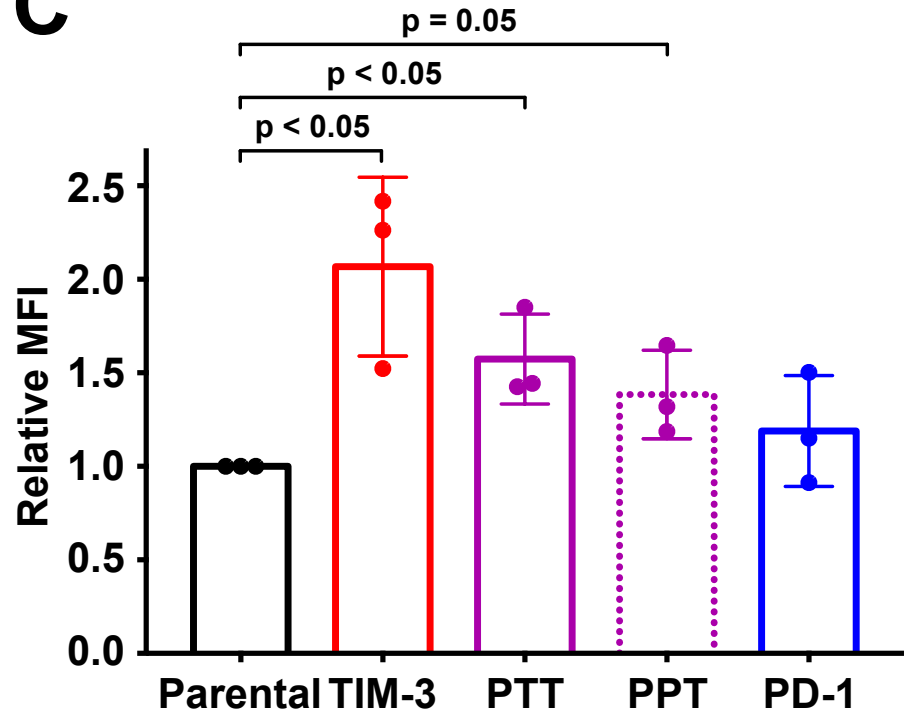

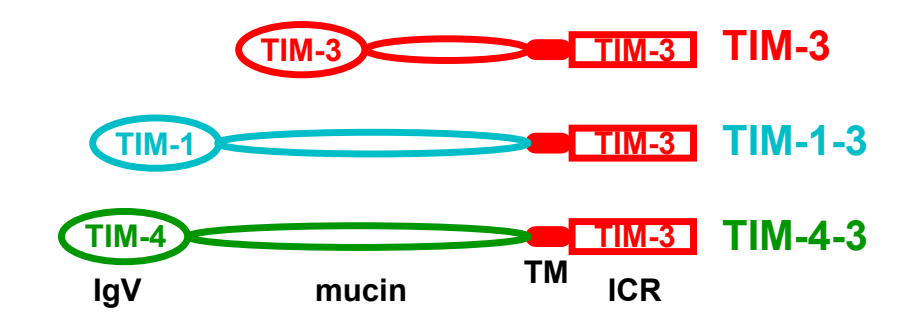

$\mathbf{E}$
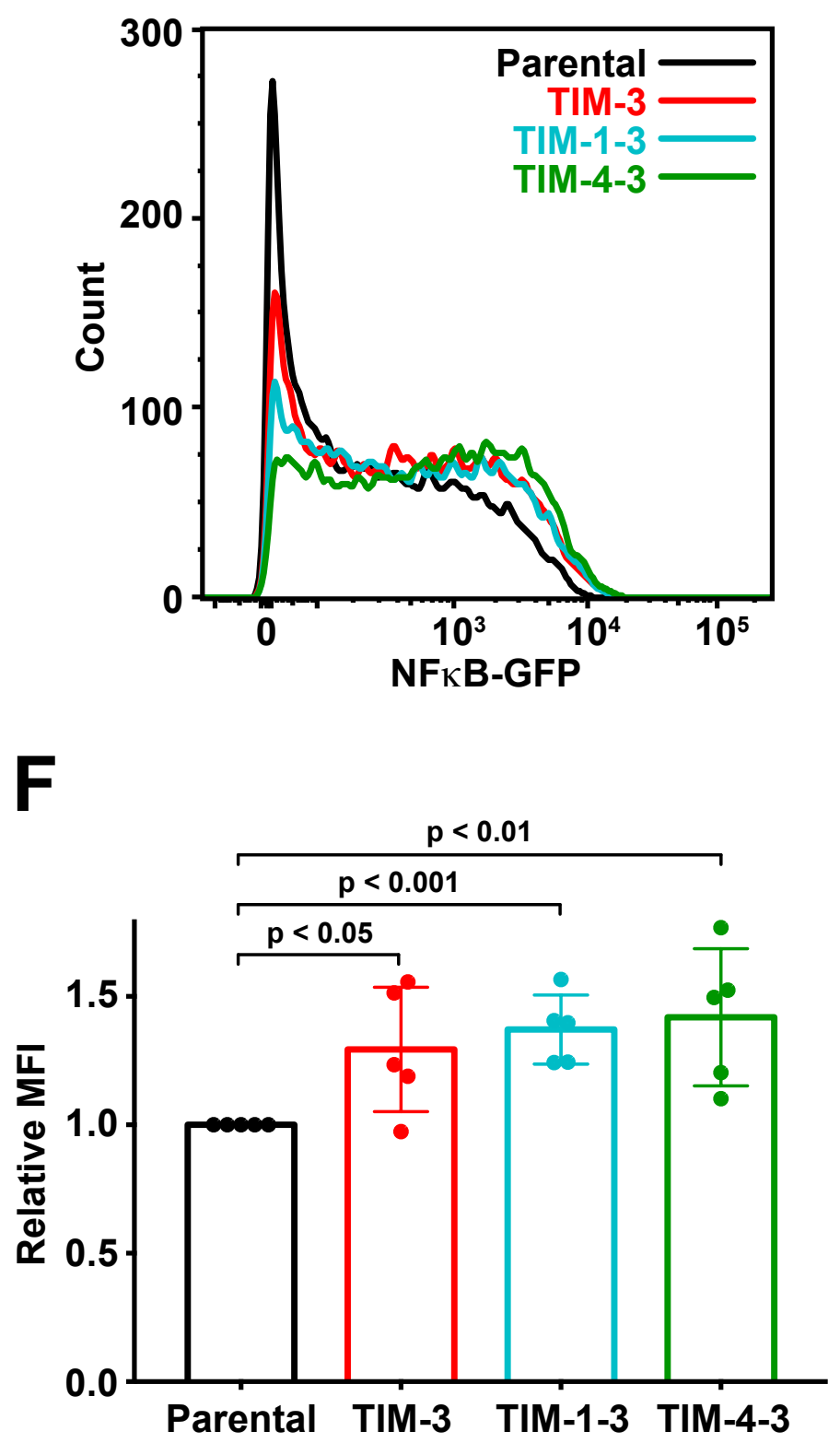

Figure 3 


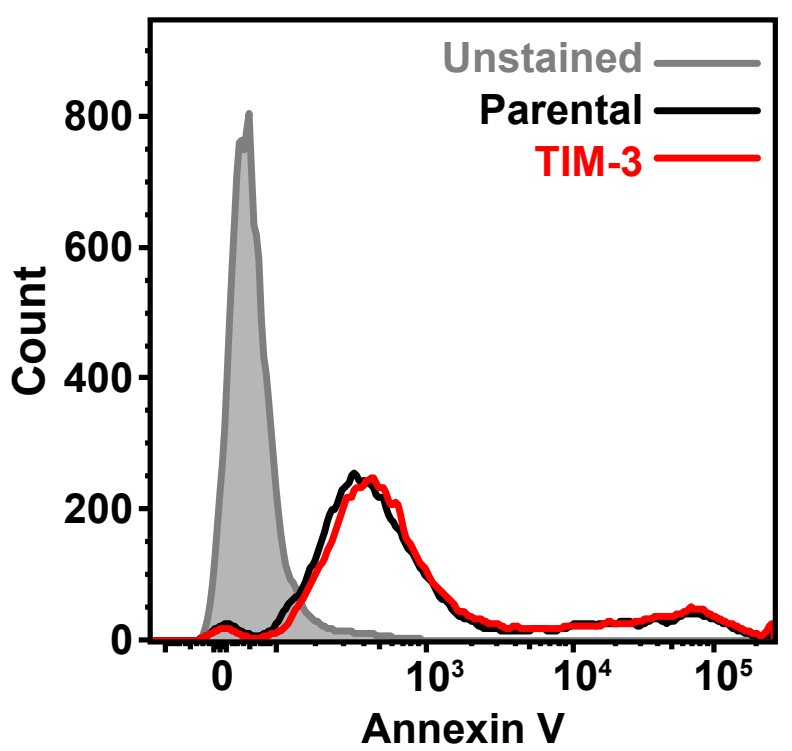

B
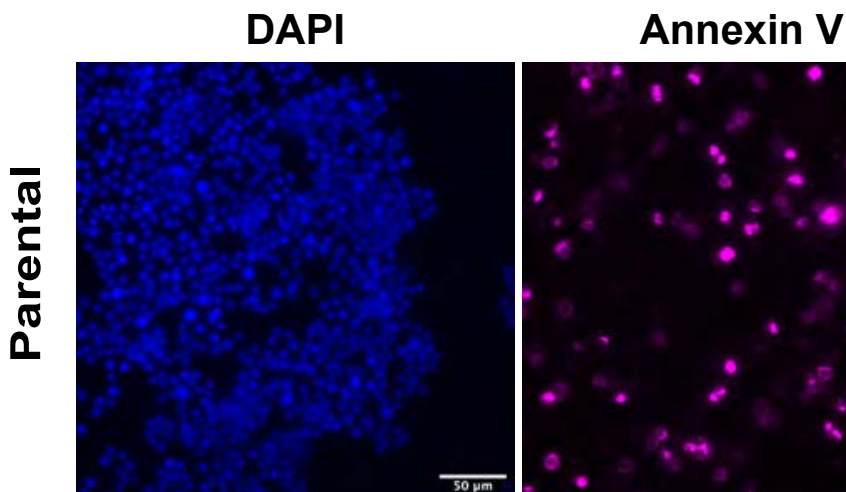

Merge
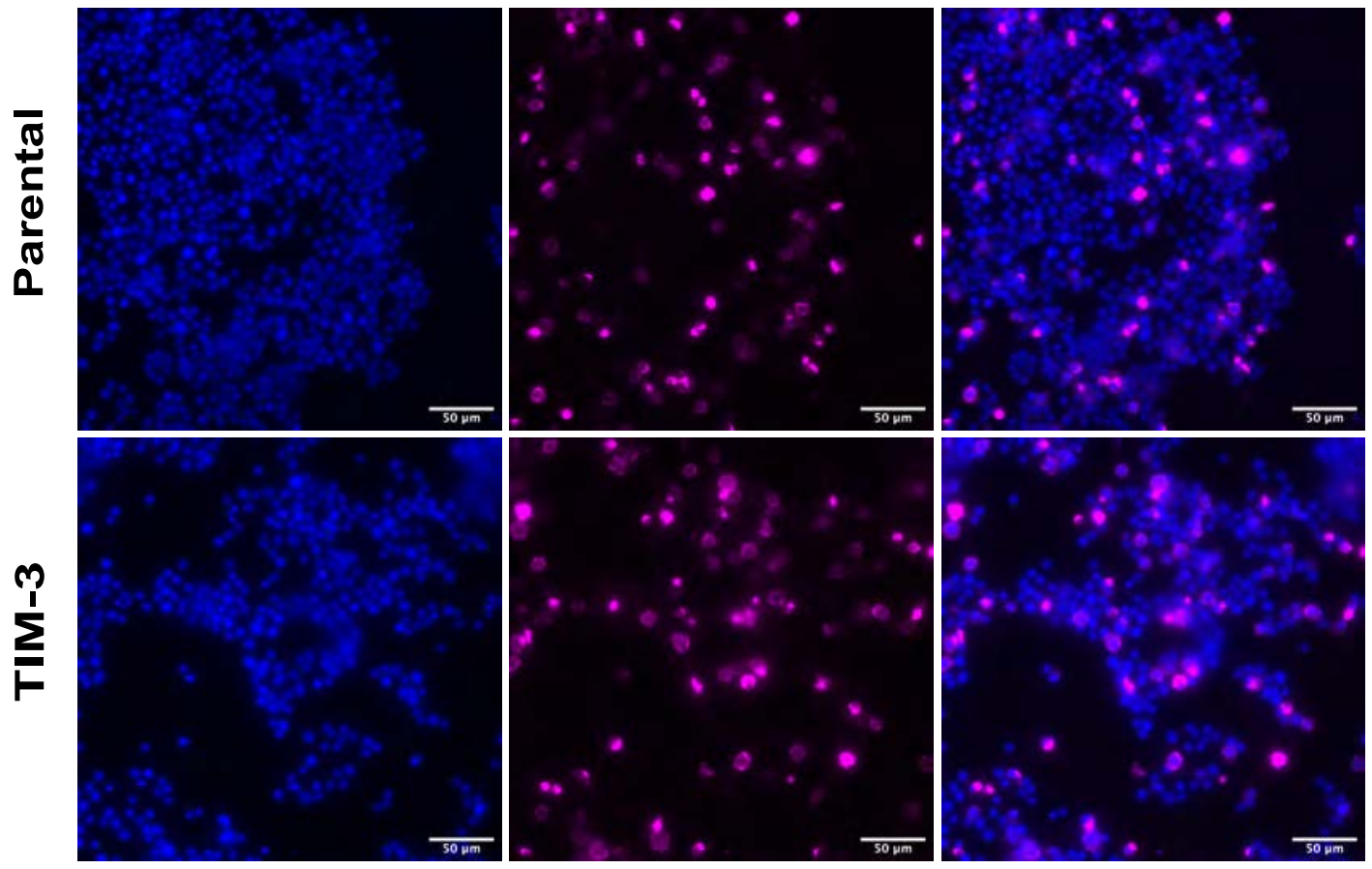

Figure 4

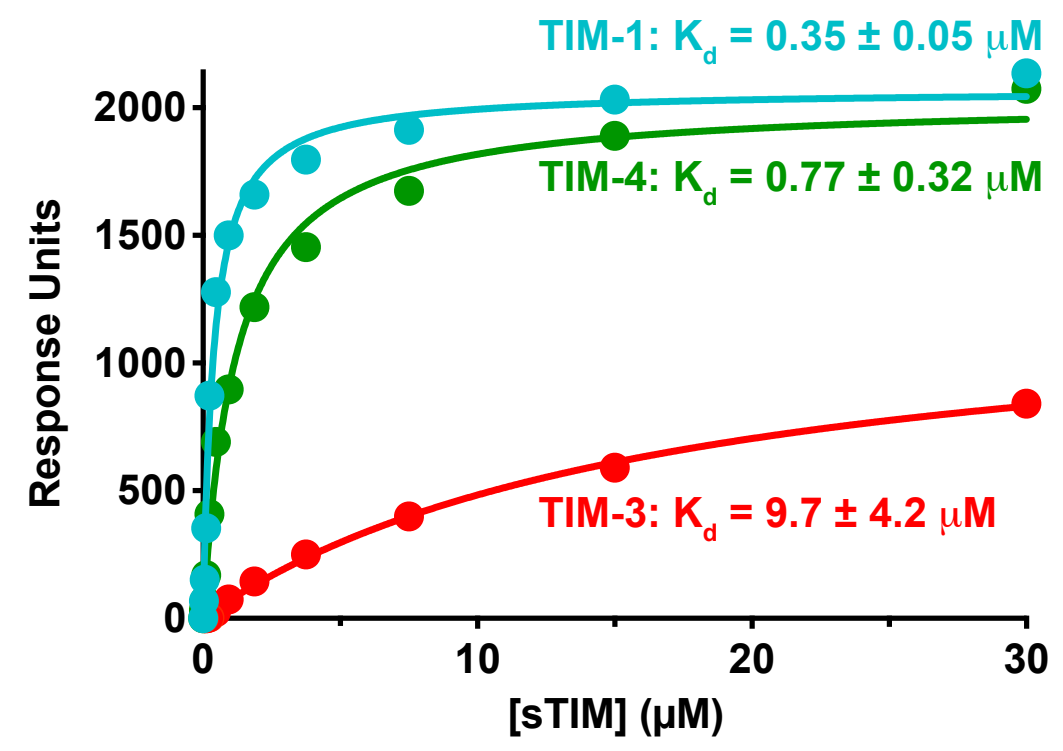




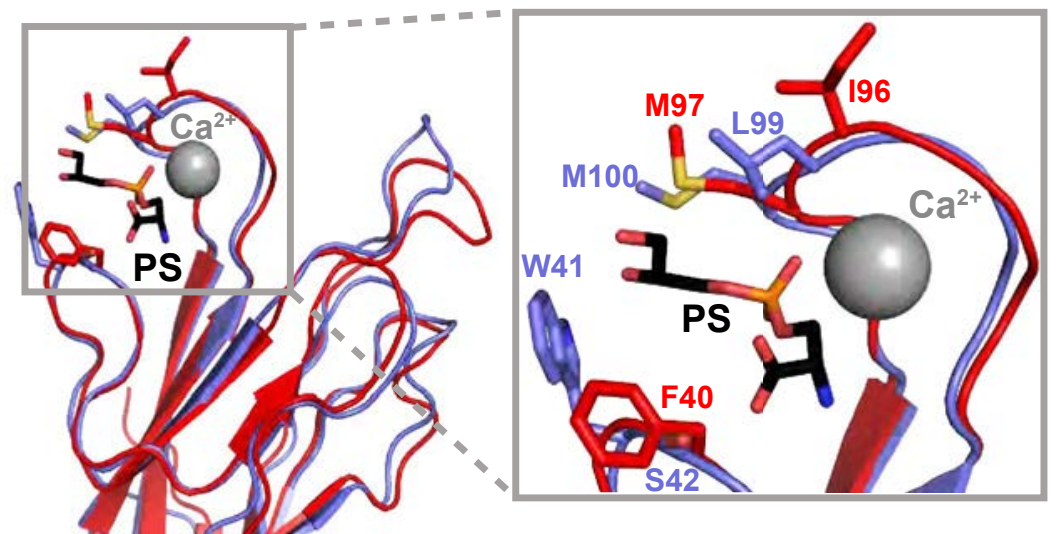

hTIM-3

mTIM-3

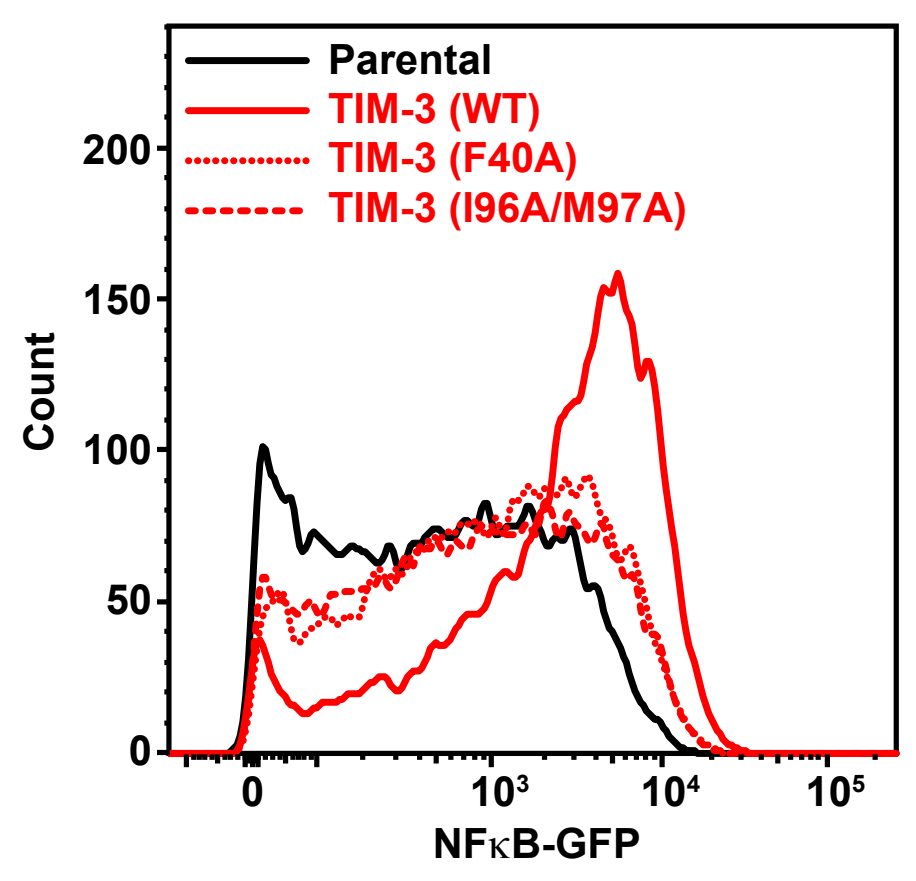

E

\section{$\alpha C D 3+\alpha C D 28$}

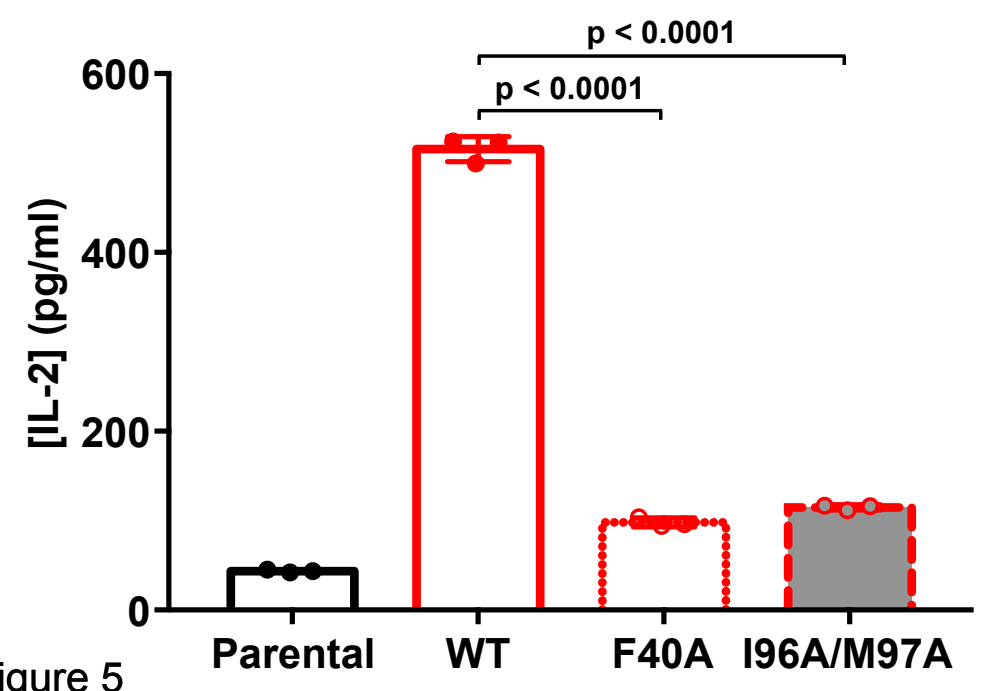

D
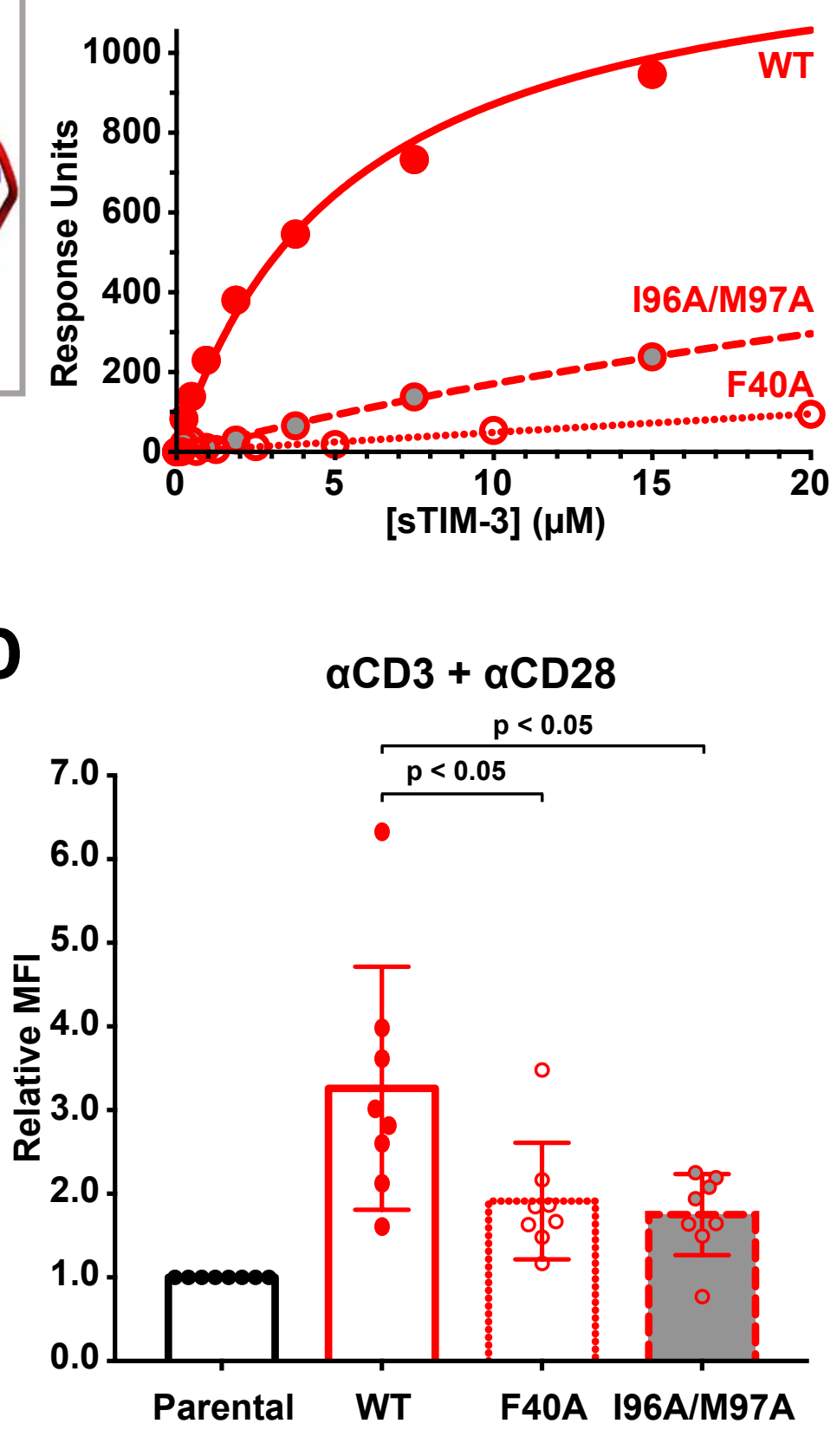

F

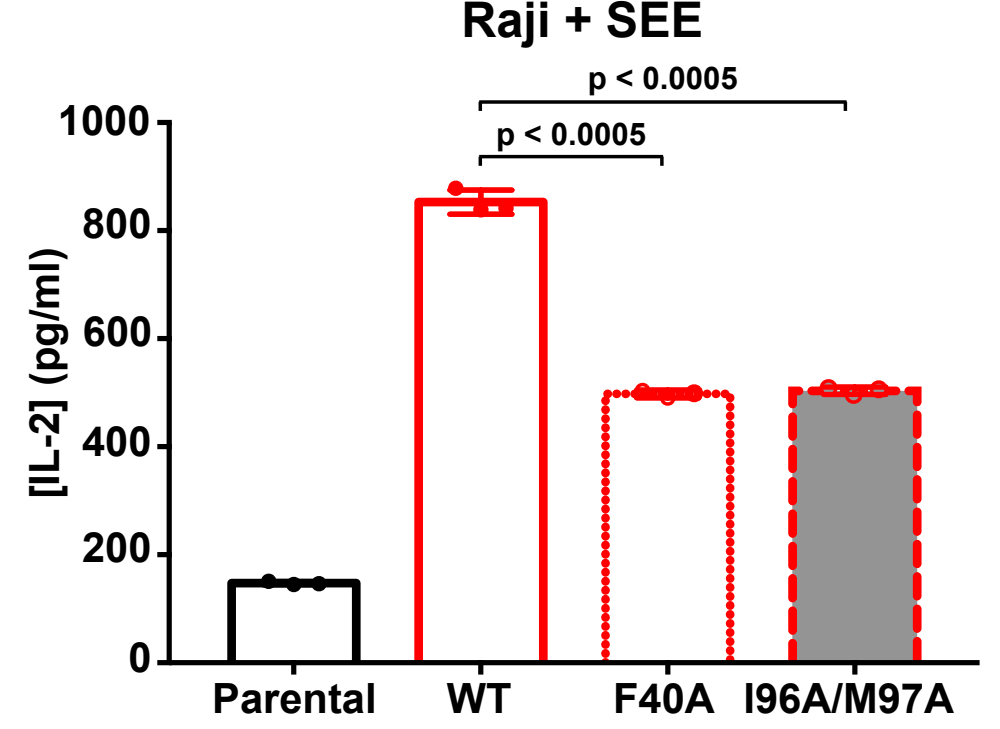


A

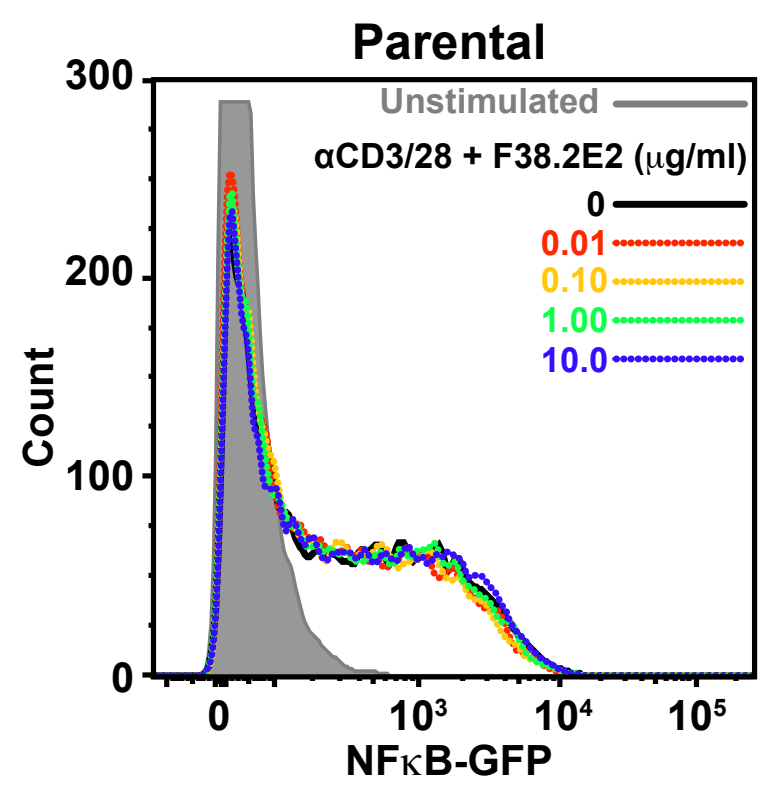

D

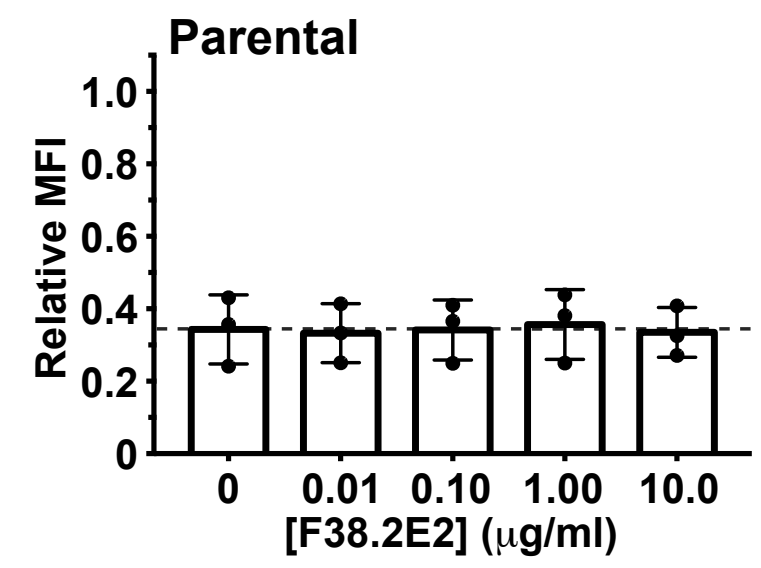

B
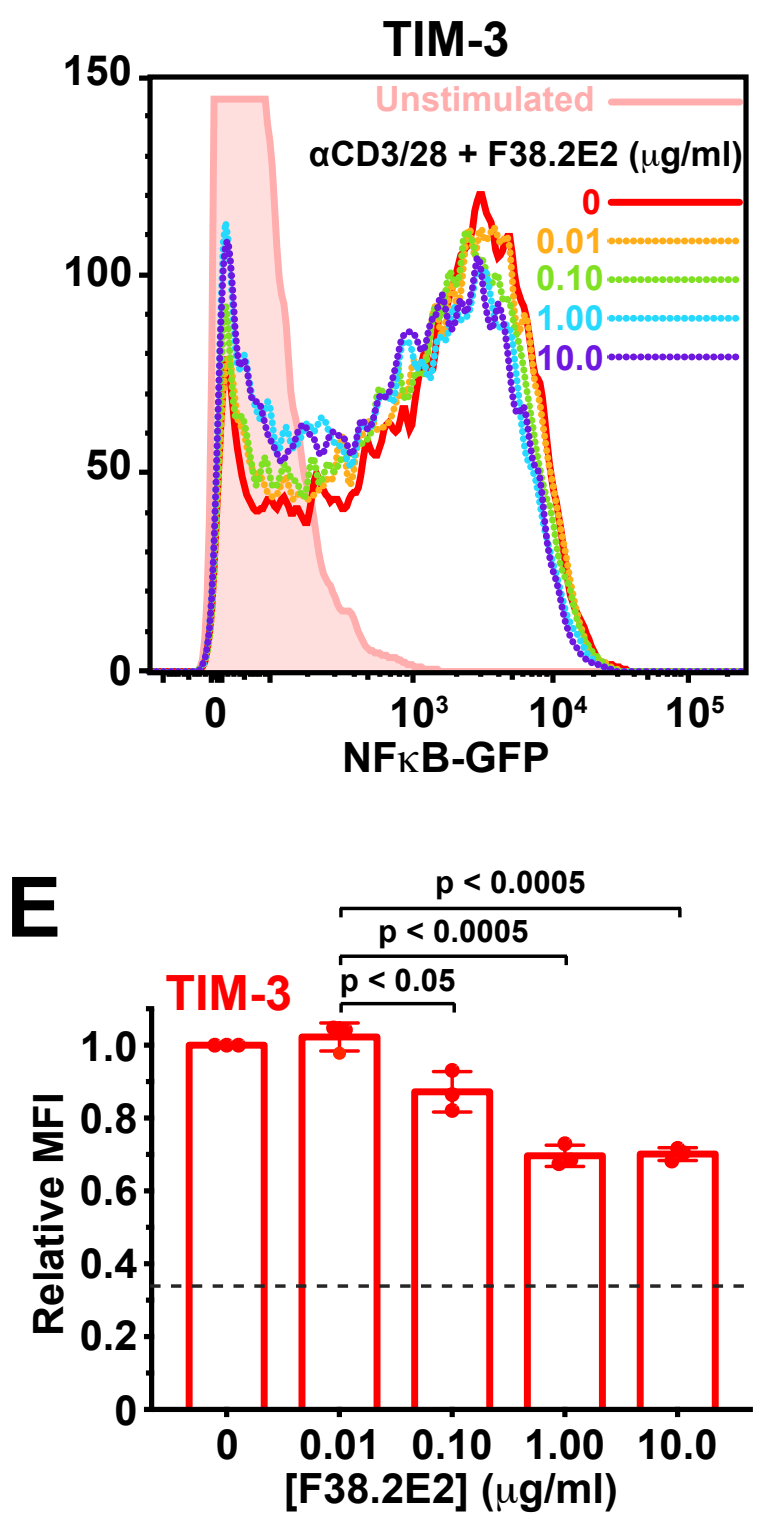

C

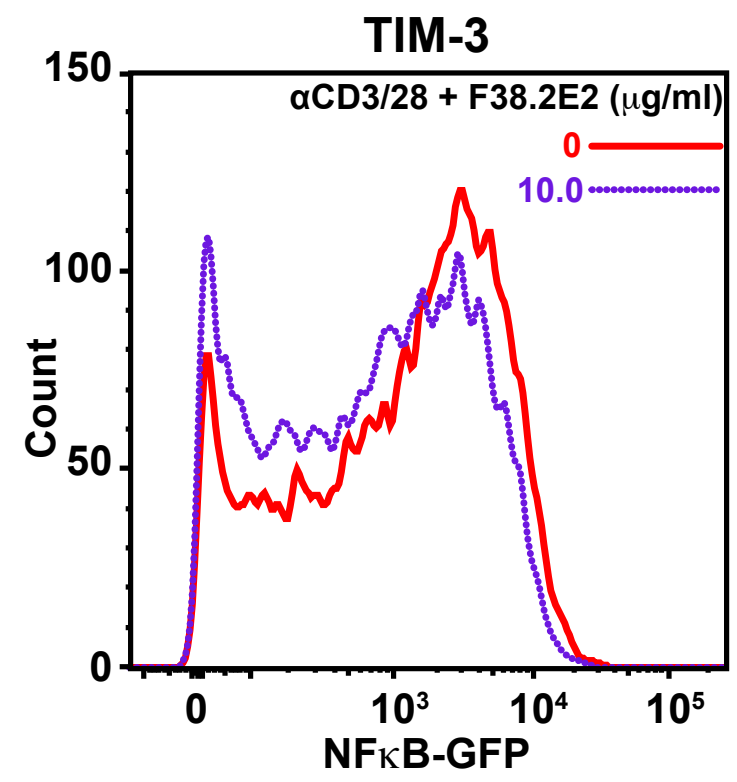

F

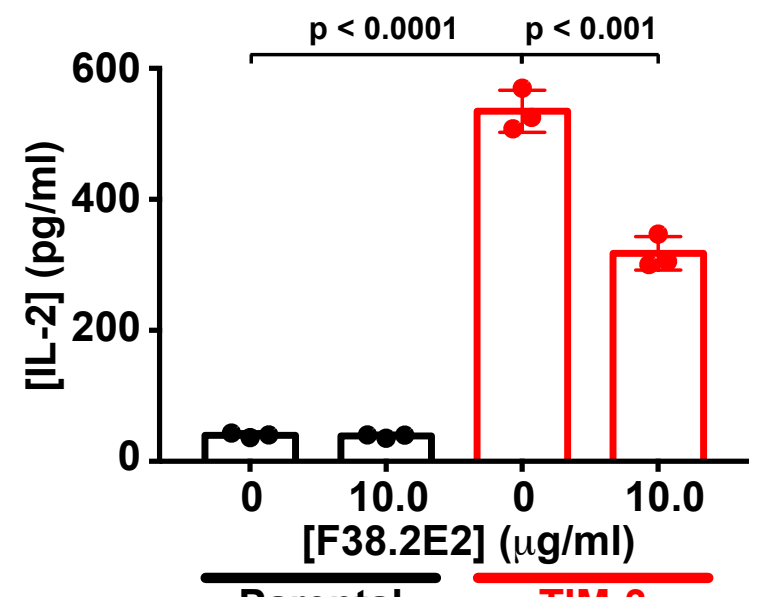

